\title{
Expressive suppression as an obstacle to social change: Linking system justification, emotion regulation, and collective action
}

\author{
Nevin Solak ${ }^{1}\left[\right.$ Maya Tamir ${ }^{2} \cdot$ Nebi Sümer $^{3} \cdot$ John T. Jost $^{4} \cdot$ Eran Halperin $^{2}$ \\ Accepted: 1 April 2021 / Published online: 12 June 2021 \\ (c) The Author(s), under exclusive licence to Springer Science+Business Media, LLC, part of Springer Nature 2021
}

\begin{abstract}
Research on system justification theory suggests that justifying the societal status quo decreases negative emotions, leading to less collective action. In this investigation, we propose that the degree to which negative emotions mediate the link between system justification and collective action may depend upon whether individuals tend to suppress the expression of their negative emotions. We tested this hypothesis in the diverse socio-political contexts of Turkey, Israel, and the U.S. In one correlational study (Study 1) and three experimental studies (Studies 2-4), we observed that the link between system justification and willingness to participate in collective action through anger (Studies 1-2 and 4) and guilt (Study 3) was moderated by expressive suppression. We found that negative emotions mediated the association between system justification and collective action among those who suppress the expression of their emotions less frequently, but not those who use expressive suppression more frequently. These findings suggest that emotion regulation may undermine, rather than facilitate, efforts to engage in collective action even among people who are low in system justification.
\end{abstract}

Keywords System justification - Emotion regulation $\cdot$ Expressive suppression $\cdot$ System-based anger $\cdot$ Collective guilt . Collective action

Collective action is an important pathway to social change aimed at promoting equality. The term is defined as any shared effort designed "to challenge or protect the status quo" whether it is "conducted by low-status groups, highstatus groups, or groups not distinguished by status position" (Becker, 2012, p.19). Negative emotions can be a powerful engine for collective action-especially when the actions of others, including authority figures, are perceived to be unjust or illegitimate (e.g., Solak, Reifen Tagar, CohenChen, Saguy, \& Halperin, 2017; Van Zomeren et al., 2004). Research based on system justification theory indicates that people who justify the societal status quo report less

Nevin Solak

nevin.solak@gmail.com

$\bowtie$ Eran Halperin

eran.halperin@mail.huji.ac.il

1 TED University, Ankara, Turkey

2 Department of Psychology, The Hebrew University of Jerusalem, Jerusalem, Israel

3 Sabancı University, Istanbul, Turkey

4 New York University, New York, NY, USA negative emotions both in general and in specific contexts (e.g., socio-political context), and they are less likely to engage in collective action compared to those who do not justify it (see Jost, 2020).

However, not everyone who is dissatisfied with the social system participates in collective action. Collective action researchers have identified various structural and psychological factors that explain why people fail to engage in collective action. Reasons for non-participation include lack of motivation, lack of sympathy for the movement, presence of structural barriers, fear of being associated with people who are perceived as "extremists", network disconnectedness, and concerns about the "loss of self" (Hensby, 2017; Klandermans \& Oegema, 1987; Klandermans \& Van Stekelenburg, 2014; Stuart et al., 2018). Because participating in collective action entails substantial social, material, and psychological costs (Morgan \& Chan, 2016), engaging in self-regulatory processes might be less costly than the pursuit of social change.

Even if people are in an upsetting or frustrating political context, they may be unlikely to protest against the status quo to the extent that they engage in strategies of downward emotion regulation (Ford, Feinberg, Lam, Mauss, \& John, 
2018). Emotion regulation involves the ways in which individuals influence which emotions they have, when they have them, and how they experience and express those emotions (Gross, 1998, 2014). If system justification influences collective action at least in part by shaping emotions (Osborne et al., 2019), then the effect of system justification on collective action may depend on whether and how people regulate these emotions in socio-political contexts. To address this hypothesis, we investigated whether suppressing one's emotions toward the status quo undermines social change by weakening the link between system justification and negative emotions. In particular, we propose that people who are dissatisfied with the system but regulate their emotions through expressive suppression would be less likely to express negative emotions such as anger and guilt and would therefore be less supportive of collective action.

\section{System justification theory, emotions, and collective action}

System justification theory offers a social-cognitive analysis of the individual's motivation to defend and justify the existing social systems. It suggests that people are motivated to defend, justify, accept, rationalize, and maintain the social, political, and economic systems in which they live and work (Jost, 2020).

People's system justification tendencies are associated with their emotional experiences. Adopting system justification beliefs increases subjective well-being, positive affect, life satisfaction, a subjective sense of security, and reduces moral outrage, cognitive dissonance, anger, frustration, and helplessness (Goudarzi, Pliskin, Jost, \& Knowles, 2020; Jost, Wakslak, \& Tyler, 2008; Li et al., 2020; Harding \& Sibley, 2013; Napier et al., 2020; Suppes et al., 2019; Rankin et al., 2009; Vargas-Salfate et al., 2018; Wakslak et al., 2007).

According to appraisal theories of emotions, appraisals of specific events influence emotions and action tendencies (Frijda et al., 1989; Moors et al., 2013). Motivations associated with socio-political ideologies can shape appraisals and subsequent emotions (e.g., Jost, 2017). As such, system justification may influence emotional experiences by affecting the appraisals of specific events, thereby influencing emotional reactions. For example, perceiving injustice can evoke anger at the social system; however, if individuals think that the social system works well, they would be less likely to appraise the situation as unjust and less likely to feel angry.

In addition to shaping emotional reactions via appraisals, system justification can guide emotion regulation by motivating people to cultivate certain emotions and avoid other emotions. To the extent that people regulate emotions for instrumental reasons (see Tamir, 2016), those high in system justification may be motivated to regulate their emotions in a way that helps to defend and protect the social system. In this sense, system justification can shape emotional experiences not only by shaping emotional reactions (via appraisals) but by shaping emotion regulation as well. Although system justification may shape emotion regulation, it is not in itself a form of emotion regulation. Justifying the system may lead people to try to change their emotional reactions under certain circumstances, and when it does, it is likely to do so through the implementation of diverse emotion regulation strategies.

The idea, then, is that justifying the status quo shapes emotional experiences, and these emotional experiences may promote thinking and behaving in the service of the status quo (Jost et al., 2017; Osborne et al., 2019). For instance, Wakslak and colleagues (2007) showed that activating a system justification mindset reduced general negative affect and moral outrage (i.e., feelings of anger and distress associated with inequality) and that this reduction in moral outrage was associated with less support for redistributive policies (e.g., willingness to donate money). Similarly, a study of teachers who were members of a national union revealed that system justification was negatively associated with anger about the government's position on teachers' pay, and that anger mediated the relationship between system justification and willingness to engage in non-disruptive protest (Jost et al., 2012). These studies demonstrate that affective reactions mediate the link between system justification and attitudes and behaviors related to social stability ( $v s$. social change). However, the process is not fixed. In this research program, we propose that the degree to which negative emotions mediate the link between system justification and collective action may depend on the extent to which people regulate their emotions by suppressing their expression.

There is limited research on the relationship between emotion regulation and collective action (for an exception, see Borders \& Wiley, 2019). A recent study by Ford et al. (2018) demonstrated that even in an upsetting political context, such as the emotionally charged 2016 U.S. elections and the Trump presidency, Clinton voters who used reappraisal to manage their politics-related emotions were less likely to take political action. In the present study, we expand on this important work in two meaningful ways.

First, we consider the possibility that there may be emotion regulation strategies, other than cognitive reappraisal, that undermine support for collective action. In this study, we focused on expressive suppression, which is a commonly used and widely studied strategy that reduces emotionally expressive behavior when the individual is emotionally aroused (Gross \& Levenson, 1993). Expressive suppression is potentially relevant to collective action because inhibition of the expression of negative emotions is likely to influence both the personal and the social implications of such 
emotions (Butler et al., 2003; Tackman \& Srivastava, 2016). For instance, a person who hides her anger may avoid acting in a confrontational manner, leading others to become less confrontational as well (Langner et al., 2012).

Second, whereas the research by Ford and colleagues (2018) targeted voters whose candidates had lost the elections, we focus on individuals who are even more inclined to participate in collective action, namely those who are low (vs. high) in system justification motivation. We hypothesized that even people who are relatively low in system justification would be unlikely to protest against the status quo to the extent that they engage in expressive suppression.

\section{Regulating emotions by expressive suppression}

People engage in emotion regulation to either increase or decrease emotional experiences and expressions in order to achieve higher-order goals (Tamir, 2016). To regulate emotions, people may use a variety of regulation strategies (Webb et al., 2012). As noted above, one strategy is expressive suppression, which refers to the inhibition of overt emotionally expressive behavior (Gross \& Levenson, 1993). According to the process model of emotion regulation, expressive suppression is a response-focused strategy that follows the onset of emotional experiences. Expressive suppression is effective in decreasing the overt expression of emotions (Gross, 1998).

Individuals differ in their tendency to suppress emotions, so that some people suppress their emotions more often than others (Gross \& John, 2003). Expressive suppression also varies across social contexts, so that people are more likely to suppress their emotions in some situations than others (Gross \& Levenson, 1993). Research on emotion regulation has examined the interpersonal implications of expressive suppression, focusing primarily on close relationships. Suppressing emotions either chronically or upon instruction is related to various negative outcomes for the individual and the quality of the relationship (Chernovsky \& Hunt, 2017; Gross, 2002). Suppression, for example, is linked to increased sympathetic responding (Gross \& Levenson, 1993), impaired memory (Richards \& Gross, 1999), and lower levels of social satisfaction and interpersonal closeness (English \& John, 2013; Srivastava et al., 2009).

Few studies have examined the effects of expressive suppression on political and/or intergroup behavior (for an exception, see Burns et al., 2008). This is despite the fact that the expression of certain emotions, such as anger and guilt, play an important role in promoting active social change and fighting for social justice (e.g., Brody, 2000; Gill \& Matheson, 2006; Halperin, 2016; Wakslak et al., 2007). In the current research, therefore, we investigated whether expressive suppression in socio-political contexts would affect social and political reactions.

We focused on two negative emotions, anger and guilt, because they motivate action to correct injustice (Halperin, 2016; Shepherd et al., 2013) and confront the source of disadvantage (Branscombe \& Doosje, 2004; Van Zomeren et al., 2004). Conversely, suppressing negative emotions pertaining to injustice is likely to attenuate the effects of emotion on behavior and to maintain the status quo. For example, women who were led to feel angry and then instructed to suppress their emotional expression were less likely to endorse collective action to change the status quo (Gill \& Matheson, 2006). Our study extends this prior line of work by addressing the possibility that expressive suppression moderates the link between system justification and emotions, thereby weakening support for collective action. From the perspective of system justification, then, by inhibiting the expression of negative emotions expressive suppression is likely to reinforce responses that perpetuate, justify, and bolster existing social arrangements. Expressive suppression may serve to protect ingroup cohesion (Matsumoto et al., 2008) and reduce social conflict (Jack \& Dill, 1992), but it also maintains social power (Langner et al., 2012), and reinforces intergroup inequality (Jack, 2011).

In the current research program, we examined the effect of expressive suppression in socio-political contexts as a moderator rather than an independent variable. Because expressive suppression does not alter the appraisals of emotion-inducing events, no changes in emotional experience were expected (Butler \& Gross, 2004). Thus, expressive suppression does not change feelings of anger or guilt per se. Instead, we hypothesized that it would subdue the impact of system justification on emotions.

Because collective action not only requires experiencing certain emotions but also the public expression of dissatisfaction with the status quo, when individuals engage in expressive suppression, they might express less intense emotions and should be less likely to participate in collective action against social injustice. This is especially likely to be the case for individuals who are low in terms of system justification tendencies, because they ordinarily would be more likely to protest. For individuals who are high in terms of system justification tendencies, expressive suppression will not be as consequential, because these individuals are unlikely to experience or express negative emotions about the social system under any circumstances.

Therefore, we hypothesized that-even or especially among people who are not motivated to justify the systemthose who tend to suppress the expression of anger or guilt in relation to the social system would be less motivated to confront those who are responsible for the unequal distribution of societal resources, compared to those who do not engage in expressive suppression. Furthermore, we expected 
that expressive suppression would moderate the negative association between system justification and negative emotions, thereby undermining the motivation to participate in collective action.

\section{Overview of present research}

We investigated this hypothesis in four studies in which system justification and expressive suppression were either measured as an individual difference variable or manipulated. We conducted a correlational study in Turkey (Study 1) and carried out experiments in Turkey (Study 2) and Israel (Study 3) in which we manipulated a system justification mindset and measured participants' emotions and willingness to participate in collective action. Finally, we conducted an experiment in the U.S. (Study 4), in which both system justification and expressive suppression were manipulated. We assessed anger associated with the overarching social system (i.e., system-based anger; Solak et al., 2012) in Studies 1, 2, and 4 and collective guilt for actions committed on behalf of the status quo in Study 3 (cf. Doosje et al., 1998).

Because the emotion items referred to emotions evoked by socio-political contexts (e.g., Turkey's social system), we focused on expressive suppression within specific sociopolitical contexts rather than expressive suppression as a general trait that applies across all contexts (see Pliskin et al., 2020 , for a description of the context-sensitive approach to studying ideological factors in emotional processes). The general emotion regulation was a strategy that individuals used to regulate their emotions generally and are not necessarily related to a specific topic, issue, or domain (e.g., ERQ-Gross \& John, 2003). Research has indicated a positive correlation between general and domain-specific emotion regulation strategies (e.g., Hughes \& Gullone, 2011). We assessed expressive suppression in the socio-political domain rather than administering more general measures (see Aldao \& Tull, 2015 for contextual approach to emotion regulation; see also Burić, Sorić, Penezić, 2016, for domainspecific measures of emotion regulation in educational settings). In four studies, then, we measured the use of expressive suppression (Studies 1-3) and manipulated expressive suppression (Study 4) in the context of the socio-political system. We followed the recommendation that individual difference variables should be measured at a specificity level that matches the specificity of the predicted variables (Leary \& Hoyle, 2009).

\section{Study 1}

In Study 1, we assessed anger toward the social system in Turkey. Anger is a response to a negative event in which others' actions are appraised as unfair and unjust (Frijda et al., 1989), and it can lead individuals to take action against the source of disadvantage (Van Zomeren et al., 2004). We focused on system-challenging collective action in the political domain (Jost et al., 2017; Osborne et al., 2019), which we measured in terms of support for freedom of speech and political expression. Although these are considered to be of critical importance for a well-functioning democracy, Turkey has long been one of the most restrictive countries among Council of Europe states in terms of freedom of speech and expression (Akdeniz \& Altıparmak, 2018). For example, there have been numerous violations of freedom of expression with respect to artists, writers, journalists, academics, politicians, and ordinary citizens.

We collected data for Study 1 in 2012. In those years, the Committee to Protect Journalists (CPJ) declared Turkey to be the worst in terms of jailing journalists (ahead of Iran and China), because 49 journalists were imprisoned (CPJ, 2012, Fanack.com, 2015). We, therefore, focused on collective action in support of freedom of speech and expression in Turkey. We predicted that the link between system justification and collective action through system-based anger would depend on the tendency to use expressive suppression in the socio-political domain.

\section{Method}

\section{Participants}

Participants were 131students of the Middle East Techincal University in Turkey ( 88 females, 43 males); they ranged in age from 19 to 30 years $(M=21.60, S D=1.90) .{ }^{1}$ Sensitivity power analysis conducted through $\mathrm{G}^{*}$ Power software (Faul et al., 2009) indicated that this sample size was sufficient for detecting a small interaction effect involving expressive suppression and system justification in a regression analysis (multiple regression: $R^{2}$ increase; power $=0.80 ; \alpha=0.05$; Cohen's $\mathrm{f}^{2}=0.06$ ). Consistent with the ideological composition of the student body, 55.4\% identified themselves as leftist, $29.2 \%$ as centrist, and $15.4 \%$ as rightist.

\footnotetext{
1 The sample initially included 170 university students in Turkey, but 39 students failed to complete the study materials.
} 
Table 1 Descriptive statistics, including correlations among major study variables in Study 1

\begin{tabular}{llllll}
\hline & 1 & 2 & 3 & 4 & $M(S D)$ \\
\hline $\begin{array}{l}\text { 1. Expressive } \\
\text { suppression }\end{array}$ & - & 0.13 & -0.08 & $-0.17 *$ & $3.23(1.24)$ \\
$\begin{array}{l}\text { 2. General system } \\
\text { justification }\end{array}$ & - & $-0.67 *$ & $-0.24 *$ & $2.53(1.31)$ \\
$\begin{array}{l}\text { 3. System-based } \\
\text { anger }\end{array}$ & & - & $0.31 *$ & $4.95(1.44)$ \\
$\begin{array}{l}\text { 4. Collective } \\
\text { action }\end{array}$ & & & & & \\
\hline
\end{tabular}

Note. $N=131$

$* p<.05$

\section{Procedure}

Data were collected online. Participants received course credit for their participation in the study. ${ }^{2}$ We measured system justification first, followed by anger, collective action, and emotion regulation.

\section{Measures}

System justification System justification was assessed using the 8-item General System Justification Scale (Kay \& Jost, 2003). We adjusted the scale to the Turkish context (e.g., "Everyone in Turkey has a fair shot at wealth and happiness"; Cronbach's $\alpha=0.85)$. Participants rated their agreement on a 9 -point scale $(1=$ Strongly disagree; $9=$ Strongly agree).

Anger We measured system-based anger using three items. Participants were asked about their emotions toward Turkey's social system, order, and lifestyle (i.e., "I am feeling angry at Turkey's system and order", "As a participant in Turkey's system and order, I feel uneasy”, "As a participant in Turkey's system and order, I feel outraged"; Cronbach's $\alpha=0.77)$. Responses were given on a 7-point scale (1=Strongly disagree $; 7=$ Strongly agree $)$.

Collective action Willingness to participate in systemchallenging collective action in support of freedom of speech and expression was assessed with a single item. Participants indicated the extent to which they were willing to participate in demonstrations to increase freedom of speech and expression in Turkey (1= Strongly disagree; $7=$ Strongly agree).

\footnotetext{
2 This study included additional measures to address other research questions. These measures were listed in Solak (2015) and can be provided upon request.
}

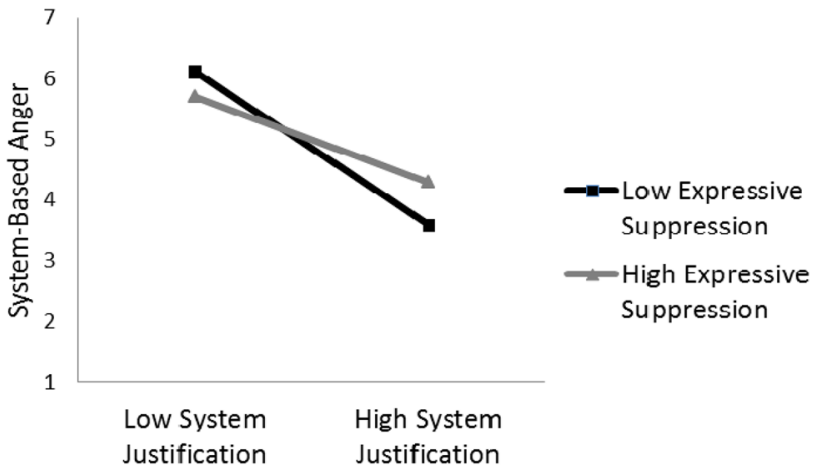

Fig. 1 Interaction between system justification and expressive suppression in Study 1

Expressive suppression We assessed individual differences in expressive suppression with the 4-item subscale of the Emotion Regulation Questionnaire (ERQ; Gross \& John, 2003), which we adjusted to focus on Turkey's social system (e.g., "When I am feeling negative emotions toward Turkey's system and order, I make sure not to express them"; Cronbach's $\alpha=0.81$ ). Responses were made on a 7-point scale (1 = Strongly disagree, $7=$ Strongly agree $)$.

\section{Results}

We first examined bivariate correlations among the major study variables (see Table 1). System justification was negatively associated with system-based anger $(r=-0.67$, $p<0.001)$ and willingness to participate in collective action $(r=-0.24, p=0.005)$. Anger was positively related to willingness to participate in collective action $(r=0.31$, $p<0.001)$.

Next, we tested the moderating effect of expressive suppression on the relationship between system justification and anger, using Hayes's (2016) PROCESS bootstrapping command with 5,000 iterations (model 1). A post-hoc power analysis for the moderation model with three predictors (multiple regression conducted via $\mathrm{G}^{*}$ Power software [Faul et al., 2009] (Cohen's $\mathrm{f}^{2}$ effect size $=0.92 ; R^{2}=0.48$ ) yielded sufficient power $(1-\beta=1.00)$. Results indicated that system justification was negatively associated with anger $(b=-0.75$, $S E=0.07, t=-10.59, p<0.001 ; 95 \%$ CI $[-0.89,-0.61])$. This effect was qualified by a significant interaction between expressive suppression and system justification $(b=0.17$, $S E=0.06, t=2.81, p=0.006 ; 95 \%$ CI [0.05, 0.29]). Here, we found that the interaction effect size $\left(\Delta R^{2}=0.03\right)$ was 0.03 (Cohen's $\mathrm{f}^{2}$ ), indicating a small-sized effect. As shown in Fig. 1, participants who were lower on system justification reported more anger when they were lower in expressive suppression $(b=-0.96, S E=0.11, t=-8.96, p<0.001$; $95 \%$ CI $[-1.17,-0.75])$. Importantly, the negative association 
Fig. 2 Direct and indirect effects of system justification on collective action as a function of expressive suppression in Study 1

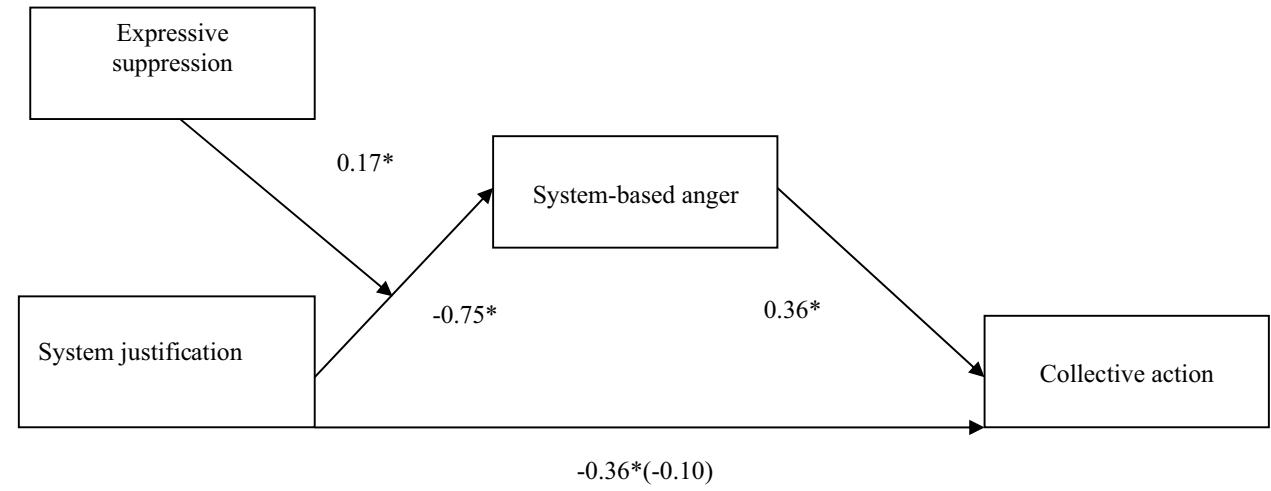

Note. ${ }^{*} p<.05$. Coefficients are unstandardized between system justification and anger was attenuated for those who tended to use expressive suppression more frequently $(b=-0.54, S E=0.10, t=-5.36, p<0.001 ; 95 \% \mathrm{CI}$ $[-0.73,-0.34])$.

Because the relationship between system justification and anger was moderated by expressive suppression, we proceeded to test a full moderated mediation model to determine whether anger mediated the relationship between system justification and collective action as a function of expressive suppression. We used Hayes's (2016) PROCESS bootstrapping command with 5,000 iterations (model 7). The model was specified with system justification as the independent variable, anger as the mediator, collective action as the outcome variable, and expressive suppression as a moderator of the relationship between system justification and anger. The moderated mediation model was significant (index of moderated mediation $=0.06, S E=0.04,95 \% \mathrm{CI}$ [0.01, 0.17]; see Fig. 2). As hypothesized, system justification was negatively associated with anger, which, in turn, was associated with collective action-especially for those who tended to use expressive suppression less frequently ( $b=-0.35, S E=0.17,95 \%$ CI [-0.70, -0.03]). The mediation effect of anger was also significant for those who tended to use expressive suppression more frequently $(b=-0.19$, $S E=0.09,95 \%$ CI $[-0.40,-0.03])$, but the effect was weaker, indicating that expressive suppression attenuated the effect of anger.

\section{Discussion}

Study 1 demonstrated that the link between system justification and willingness to participate in collective action through anger was moderated by expressive suppression. More specifically, system justification was negatively associated with system-based anger and support for collective action among those who tended to suppress the expression of their emotions less frequently. However, the association between system justification and anger was attenuated for those who tended to use expressive suppression more frequently. Although the results of Study 1 supported our hypothesis, our statistical tests of the interaction term were somewhat underpowered. Another limitation of the study is that it was correlational in nature and, therefore, does not speak to the causal role of system justification in shaping the experience of anger and willingness to participate in collective action. In Study 2, therefore, we used an experimental design in which system justification was manipulated directly.

\section{Study 2}

In Study 2, we experimentally manipulated system justification to investigate causal effects on anger and collective action, and to determine whether its effects would be moderated by expressive suppression. In Study 2, we focused on system-challenging collective actions in a variety of socio-political domains. We used a multi-item measure of collective action, which captured willingness to engage in collective action directed at changing the status quo in various ways.

To manipulate system justification, we adopted a manipulation developed by Liviatan and Jost (2014), which was based on the notion that a threat to the societal status quo activates the system justification goal (see Jost, 2020). The opportunity to affirm the system in response to the threat presumably leads individuals to restore their faith in the social system and satisfy the system justification goal. Following this rationale, in Study 3, we manipulated system justification by exposing participants to a system-threatening passage, and then in the experimental (vs. control) condition, we provided them with an opportunity to restore their belief in the status quo by affirming the existing system. We predicted that the dampening effects of system justification motivation on anger and support for collective action would be moderated by expressive suppression. 
Table 2 Descriptive statistics, including correlations among major study variables in Study 2

\begin{tabular}{|c|c|c|c|c|c|c|}
\hline & 1 & 2 & 3 & 4 & $\begin{array}{l}\text { Control con- } \\
\text { dition } \\
M(S D)\end{array}$ & $\begin{array}{l}\text { System affirmation } \\
\text { condition } \\
M(S D)\end{array}$ \\
\hline 1. Expressive suppression & - & 0.15 & $-0.21 *$ & -0.09 & $2.95(1.43)$ & $3.37(1.47)$ \\
\hline $\begin{array}{l}\text { 2. Experimental condition } \\
(0=\text { Control; } 1=\text { System } \\
\text { affirmation })\end{array}$ & & - & $-0.26^{*}$ & $-0.26^{*}$ & $0.00(0.00)$ & $1.00(0.00)$ \\
\hline 3. System-based anger & & & - & $0.39^{*}$ & $4.51(1.88)$ & $3.51(1.92)$ \\
\hline 4. Collective action & & & & - & $5.59(1.22)$ & $4.78(1.73)$ \\
\hline
\end{tabular}

Note. $N=48$ in control condition; $N=50$ in system affirmation condition $* p<.05$

\section{Method}

\section{Participants}

Study 2 was conducted in 2013. Participants were 98 university students from Abbant Izzet Baysal University in Turkey (64 females, 33 males, and 1 unidentified). ${ }^{3}$ Consistent with the ideological composition of students at this university, $37.9 \%$ of participants were rightist, $28.4 \%$ were centrist, and $33.7 \%$ were leftist.

Sensitivity power analysis for the interaction term between expressive suppression and system justification indicated that the sample size of 98 was sufficient to detect a small interaction effect between expressive suppression and system justification in a regression analysis (multiple regression: $R^{2}$ increase; power $=0.80 ; \alpha=0.05$; Cohen's $\left.\mathrm{f}^{2}=0.08\right)$. A sensitivity power analysis for the difference between two independent means (two groups) using $G^{*}$ Power software (Faul et al., 2009) indicated an effect size of 0.57 to indicate the minimal detectable medium-sized effect.

\section{Procedure}

Participants were informed that the study, which was conducted in a classroom, examined individuals' attitudes

\footnotetext{
3 Originally, 168 university students were asked to complete the study. Participants received paper and pencil materials immediately before the class and were informed that they were not required to answer all of the questions. Seventy participants failed to complete the study materials and were therefore excluded from analyses. Specifically, 106 (out of 168) participants completed the first part of the experimental manipulation (writing about 5 characteristics). Of these, 103 participants completed the second part of the experimental manipulation (writing a short story). Finally, 98 of these 103 participants completed all of the scales. The participants who were excluded from the analysis did not differ statistically from those who were retained in terms of gender, $\chi^{2}(1,162)=1.62, p=.201$, or age, $t(155)=0.47, p=.638$.
}

toward different social issues. ${ }^{4}$ First, participants read a system-threatening text, which was adapted from Kay, Jost, and Young (2005) and adjusted to the Turkish context; it therefore focused on social problems in Turkey. After reading the passage, participants were assigned either to a system affirmation condition or control condition. In the system affirmation condition $(n=50)$, participants were asked to consider themselves as participants in Turkey's system, social order, and way of life, and to list five positive aspects of Turkey's system, and write a short essay about these features. In the control condition ( $n=48)$, participants were instructed to consider themselves as students of their university, list five positive features of their university, and write a short essay about these features. Following these tasks, participants completed measures of system justification, system-based anger, collective action, and expressive suppression.

\section{Measures}

System Justification We used the same measure of system justification as in Study 1 (Cronbach's $\alpha=0.90)$. Participants rated their agreement on a 9-point scale $(1=$ Strongly disagree; $9=$ Strongly agree $)$.

Anger We used the same 3-item measure of system-based anger that was used in Study 1 (Cronbach's $\alpha=0.87$ ).

Collective action We administered 7 items designed to capture individuals' willingness to participate in collective action aimed at increasing equal access to university education, protecting the rights of ethnic minorities, increasing

\footnotetext{
${ }^{4}$ In addition to these two experimental conditions, we included two other experimental conditions as part of another study on emotions. For the purpose of that study, we also included questions regarding individual emotions, group-based emotions, group justification, system emotions (sadness, guilt/shame, fear/anxiety, happiness), and cognitive reappraisal. These measures are described in Solak (2015) and can be provided upon request.
} 


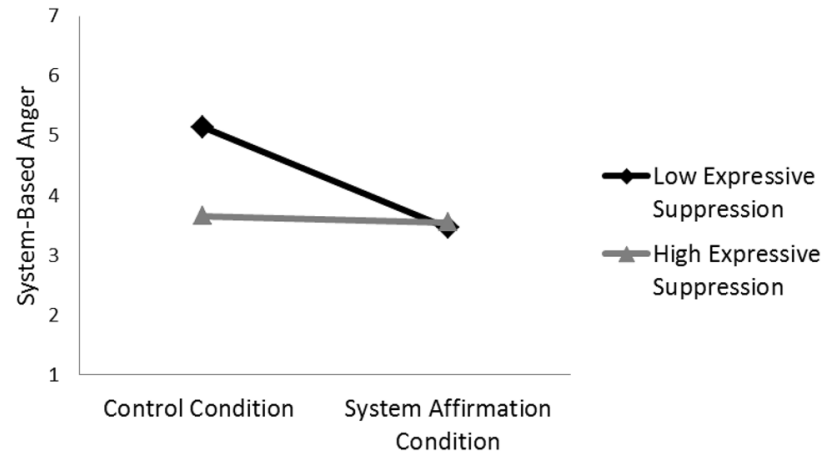

Fig. 3 Interaction between experimental condition and expressive suppression in Study 2

freedom of speech, increasing financial assistance to homeless people, and protesting against gender disparities in the workplace. Sample items included: "I am willing to participate in actions to increase financial assistance for homeless people," and "I am willing to participate in actions in favor of increasing freedom of speech and expression in society" (Cronbach's $\alpha=0.91)$. Responses were provided on a 7-point scale $(1=$ Strongly disagree $; 7=$ Strongly agree $)$.

Expressive suppression We used the same measure of expressive suppression toward Turkey's system as in Study 1 (Cronbach's $\alpha=0.81)$.

\section{Results}

Descriptive statistics, including correlations among study variables, are provided in Table 2. In terms of the manipulation check, participants assigned to the system affirmation condition $(M=4.09, S D=1.90)$ scored higher on general system justification than those assigned to the control condition $(M=3.13, S D=1.71), t(96)=-2.63, p=0.010$, Cohen's $d=0.53$. This suggests that the opportunity to affirm the social system elevated system justification tendencies, relative to the control condition, rather than merely satiating the goal, as in research conducted by Liviatan and Jost (2014) in the U.S. A post-hoc power analysis showed that this analysis provided $74 \%$ power to detect effect size $d$ in independent-samples t-test (two-tailed).

Participants also reported lower levels of system-based anger and support for collective action in the system affirmation condition $(M=3.51, S D=1.92$, and $M=4.78$, $S D=1.73$, respectively) than in the control condition ( $M=4.51, S D=1.88$, and $M=5.59, S D=1.22$, respectively), $t(96)=2.61, p=0.011$, Cohen's $d=0.53 ; t(88.09)=2.68$, $p=0.009$, Cohen's $d=0.54$, respectively. At the same time, the system affirmation manipulation did not significantly affect expressive suppression, $t(96)=-1.45, p=0.151$, Cohen's $d=0.29$.

As in Study 1, to determine whether the effects of system justification were moderated by expressive suppression, we used Hayes' (2016) PROCESS bootstrapping command with 5,000 iterations (Model 1). A post-hoc power analysis for the moderation model with three pedictors (multiple regression conducted using $\mathrm{G}^{*}$ Power software (Faul et al., 2009 ) yielded sufficient power (Cohen's $f^{2}$ effect size $=0.16$; $\left.R^{2}=0.14 ; 1-\beta=0.92\right)$. We observed that the system affirmation manipulation significantly decreased anger $(b=-0.90$, $S E=0.38, t=-2.38, p=0.020 ; 95 \%$ CI $[-1.65,-0.15])$, but this main effect was qualified by a significant interaction $(b=0.55, S E=0.26, t=2.07, p=0.041 ; 95 \%$ CI $[0.02,1.07])$. The interaction effect size $\left(\Delta R^{2}=0.04\right)$ was 0.04 (Cohen's $\mathrm{f}^{2}$ ), indicating a small-sized effect. As shown in Fig. 3, for participants who suppressed emotions less frequently, those who were induced to affirm the system reported less systembased anger compared to those who were assigned to the control condition $(b=-1.68, S E=0.53, t=-3.16, p=0.002$; 95\% CI $[-2.74,-0.62])$. On the other hand, for participants who suppressed emotions more frequently, system affirmation had no effect on anger $(b=-0.11, S E=0.54, t=-0.20$, $p=0.84 ; 95 \%$ CI $[-1.18,0.96])$.
Fig. 4 Direct and indirect effects of system justification on collective action as a function of expressive suppression in Study 2

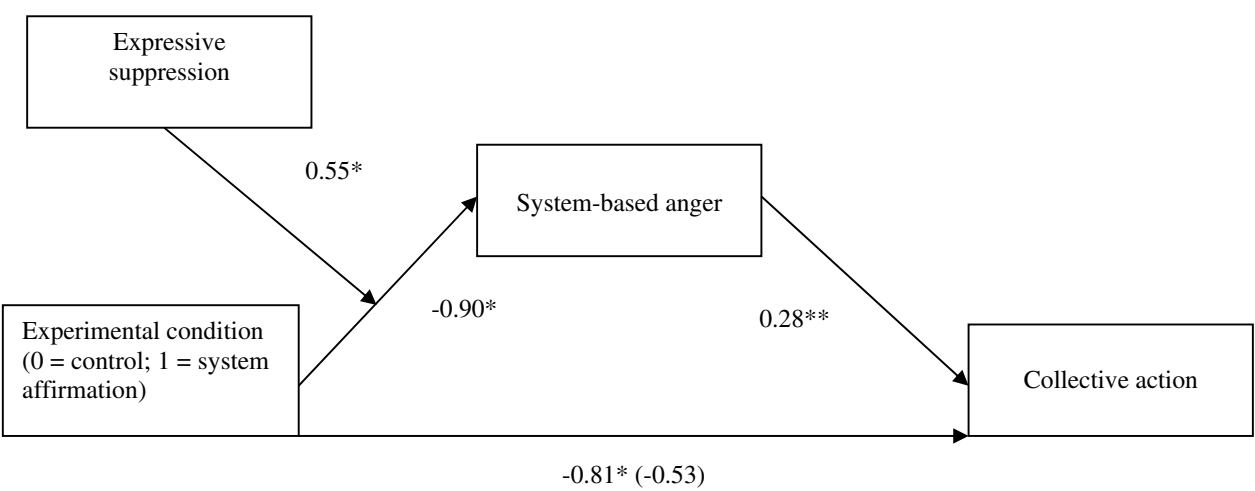

Note. ${ }^{*} p<.05$. Coefficients are unstandardized. 
We proceeded to test a moderated mediation model in which anger mediated the relationship between the manipulation of system affirmation and collective action as a function of expressive suppression using Hayes's (2016) PROCESS bootstrapping command with 5000 iterations (Model 7 ). The moderated mediation model was significant (index of moderated mediation $=0.15, S E=0.10,95 \%$ CI $[0.003$, 0.41]; see Fig. 4). In line with our hypothesis, for participants who used expressive suppression less frequently, system affirmation decreased anger, which in turn, influenced willingness to engage in collective action $(b=-0.46$, $S E=0.24,95 \%$ CI[-1.08, -0.11]). For those who used expressive suppression more frequently, anger did not mediate the effect of system affirmation on collective action $(b=-0.03$, $S E=0.15,95 \%$ CI $[-0.36,0.26])$.

\section{Discussion}

In Study 2, we demonstrated that an experimentally induced system justification mindset exhibited a causal effect on collective action through reduced anger as a function of expressive suppression. For participants who tend to use expressive suppression less frequently, a system justification mindset decreased system-based anger, thereby decreasing willingness to engage in collective action. At the same time, for those who tend to use expressive suppression more frequently, inducing a system justification mindset had no effect on system-based anger.

The results of Study 2 were consistent with our hypotheses, but they should be taken with a grain of salt because some of the effect sizes we obtained were small and post hoc power analyses suggested that the comparisons between experimental conditions were underpowered. Another limitation of our first two studies is that they focused exclusively on the emotion of anger and collective action in support of social change. In Study 3, we examined the moderating role of expressive suppression in the context of a different emotion, namely collective guilt, in the context of a different type of collective action, namely efforts to redress injustices arising from a seemingly intractable conflict.

\section{Study 3}

In Study 3, as noted above, we targeted an emotion other than anger that is directly related to perceptions of injustice, namely the emotion of collective guilt. People may experience collective guilt for actions committed by members of their ingroup, even if they were neither personally involved nor responsible for the ingroup's harmful actions (Doosje et al., 1998). To experience collective guilt, people must appraise the ingroup situation as illegitimate
(Bahns \& Branscombe, 2011; Branscombe \& Miron, 2004; Miron et al., 2006). Collective guilt often plays a constructive role in intergroup conflict (Halperin, 2016), because it can mobilize people to protest against illegitimate actions taken in the past with the goal of repairing damaged intergroup relations (Mallett et al., 2008). Recent research has demonstrated that the experience of collective guilt increases participation in collective action (Solak et al., 2017).

Study 3 was conducted in the context of the IsraeliPalestinian conflict. To explore the generalizability of our approach, we used a different manipulation of system justification mindset than the one used in Study 2. The manipulation in Study 3 was based on the idea that choice restriction increases the tendency to engage in system justification processes. Previous studies have shown that when organizations implement policies that restrict their employees' freedom, people often justify the restrictive policies and react favorably to them, as long as there is no alternative to them (Kay et al., 2009; Laurin et al., 2013). For example, when people face an inescapable (vs. escapable) condition—such as prohibitions on leaving the country-they are more likely to legitimize the current status quo (Laurin et al., 2010). The idea that restricted choice increases justification of the status quo is also consistent with another line of research, which suggests that people are less likely to blame others for engaging in harmful activities when they believe that their choices were constrained (vs. unconstrained; Alicke, 2000; Botti \& Iyenger, 2004; Botti \& Macgill, 2006; Malle et al., 2014).

The same theoretical logic pertaining to restricted choice can be applied to intergroup relations. If members of the ingroup are seen as choosing to transgress against outgroup members, this can intensify blame and dissatisfaction, but the absence of choice might make the transgression seem more legitimate. Framing the ingroup's hostility toward the outgroup as not freely chosen, on the other hand, may render these actions more legitimate. Therefore, we expected that framing Israeli military policies regarding Palestinians as necessary (i.e., there is "no choice") would increase system justification, compared to framing the same policies as merely one of several possible options ("high choice"). Based on this expectation, we manipulated system justification by varying whether or not the Israeli military was perceived as having a choice when setting its policies toward Palestinians. We hypothesized that the effect of system justification on collective action through collective guilt would depend on the use of expressive suppression. 
Table 3 Descriptive statistics, including correlations among major study variables in Study 3

\begin{tabular}{|c|c|c|c|c|c|c|}
\hline & 1 & 2 & 3 & 4 & $\begin{array}{l}\text { High choice condition } \\
M(S D)\end{array}$ & $\begin{array}{l}\text { Low } \\
\text { choice } \\
\text { condition } \\
M(S D)\end{array}$ \\
\hline 1. Expressive suppression & - & -0.13 & 0.10 & 0.18 & $3.16(1.29)$ & $2.85(1.06)$ \\
\hline $\begin{array}{l}\text { 2. System justification condition }(0=\text { high choice } \\
\text { condition; } 1=\text { low choice condition })\end{array}$ & & - & $-0.32 *$ & -0.02 & $0.00(0.00)$ & $1.00(0.00)$ \\
\hline 3. Collective guilt & & & - & $0.52 *$ & $2.74(1.55)$ & $1.89(1.05)$ \\
\hline 4. Collective action & & & & - & $2.38(1.51)$ & $2.33(1.22)$ \\
\hline
\end{tabular}

Note. $N=39$ in low choice condition; $N=33$ in high choice condition

$* p<.05$

\section{Method}

\section{Participants}

A sample of 72 Jewish Israelis (40 females, 32 males), ranging from 20 to 72 years of age $(M=44.80, S D=15.55)$, participated in the study. ${ }^{5}$ Data were collected in 2016 through an online survey company (Midgam). In terms of political orientation, $56.9 \%$ of participants were rightist, $26.4 \%$ were centrist, and $16.7 \%$ were leftist. $^{6}$

Sensitivity power analysis for the interaction term (multiple regression: $R^{2}$ increase) using 0.80 as a threshold yielded an effect size of 0.11 , which indicated that the minimal detectable effect was a small to medium-sized effect in this sample. Sensitivity power analysis for difference between two independent means (two groups) using 0.80 as a threshold indicated an effect size of 0.67 , which showed that the minimal detectable effects as a medium-sized effect.

\section{Procedure}

To manipulate system justification, participants were first assigned to either a high or a low perceived choice condition. Specifically, they read a fictional newspaper article describing night raids conducted by the Israeli military on Palestinian villages and homes in Israel. The night raid is a military tactic or operational warfare mission that has a specific aim, such as preventing the target group from acting in a coordinated manner. Home night raids have been found to produce

\footnotetext{
5 A total of 96 participants were randomly assigned to one of two conditions, but only 94 identified themselves as Israeli Jews. Of those, 22 failed the reading-check questions. Therefore, the final sample consisted of 72 participants.

6 This study included additional measures to address other research questions. The data collection included measures of emotional preferences, discrete emotions, including anger and guilt items, collective action, general expressive suppression, and appraisals of the legitimacy of Israel's policies.
}

serious negative mental health consequences, especially for children (Abu Hein et al., 1993).

In the low perceived choice condition $(n=39)$, participants read that night raids were the most effective way to stop terror and violence and that Israel had no option but to conduct them. In the high perceived choice condition $(n=33)$, participants read that night raids were just one of several effective ways of addressing terror and violence and that Israel had other good options. After reading the article, participants were asked three reading check questions so that we could confirm that they had read the article. Next, participants completed measures of system justification, collective guilt concerning Israel's actions toward Palestinians, support for collective action against transgressions committed on behalf of the state of Israel, and expressive suppression.

\section{Measures}

System Justification System justification was assessed using the 8-item General System Justification Scale (Kay \& Jost, 2003). We adjusted the scale to fit the Israeli context (Cronbach's $\alpha=0.86)$. Participants rated their agreement on a 9-point scale (1= Strongly disagree; $9=$ Strongly agree $)$.

Collective guilt We assessed collective guilt about Israel's actions toward Palestinians using four items adapted from Branscombe et al. (2004) and applied to the current context. We asked participants to report how they felt when thinking about the newspaper article (e.g. "I feel guilty for Israel's actions toward the Palestinians", "Israel should feel guilty for the way it treats Palestinians", "Israel should feel responsible for the way it treats Palestinians", "Israel's policies regarding night raids on Palestinians make me feel guilty"; Cronbach's $\alpha=0.82$ ). Responses were given on a 7-point scale (1=Strongly disagree; $7=$ Strongly agree $)$.

Collective action We administered two items designed to capture the willingness to participate in collective action against Israel's policies regarding Palestinians. Sample 


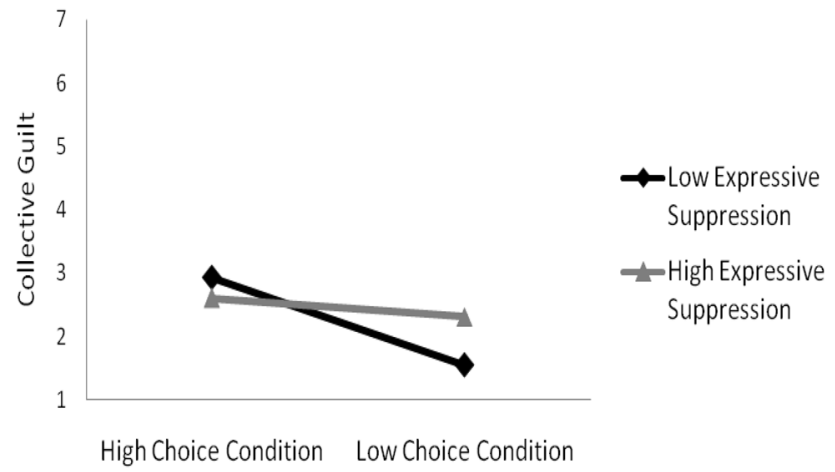

Fig. 5 Interaction between experimental condition and expressive suppression in Study 3

items included: "When I think about the article, I would like to take part in protesting against night raids conducted by Israel on civilian Palestinians", and "I am willing to participate in actions in favor of protecting the rights of ethnic minorities (e.g., Arabs in Israel, Palestinians in Israel)" ( $r=0.44, p<0.001)$. These items both tap intentions for improving the human rights of Palestinian citizens of Israel. Responses were given on a 7 -point scale $(1=$ Strongly disagree; 7 = Strongly agree).

Expressive suppression We assessed expressive suppression with the 4-item subscale of the Emotion Regulation Questionnaire (ERQ; Gross \& John, 2003) adjusted to the Israeli context. Specifically, we measured the tendency to suppress the expression of emotion toward the Israeli system (e.g., When I am feeling negative emotions toward the Israeli system, I make sure not to express them; Cronbach's $\alpha=0.73$ ). Responses were given on a 7-point scale $(1=$ Strongly disagree, $7=$ Strongly agree $)$.

\section{Results}

Correlations and other descriptive statistics are provided in Table 3. Participants assigned to the condition in which they were led to believe that Israel had no choice but to carry out night raids scored higher on general system justification $(M=5.21, S D=1.63)$ than those assigned to the condition in which other options were said to exist $(M=4.25, S D=1.55)$, $t(70)=-2.55, p=0.013$, Cohen's $d=0.60$. A post-hoc power analysis showed that the manipulation provided $71 \%$ power to detect effect size $d$ in independent-samples $t$-test (two-tailed).

Participants also reported lesser collective guilt in the low choice condition $(M=1.89, S D=1.05)$ than the high choice condition $(M=2.74, S D=1.55), t(70)=2.78, p=0.007$, Cohen's $d=0.64$. The manipulation did not affect collective action, $t(70)=0.14, p=0.888$, Cohen's $d=0.04$, or expressive suppression, $t(70)=1.11, p=0.271$, Cohen's $d=0.26$.

To determine whether the effect of system justification on collective guilt was moderated by expressive suppression, we again used Hayes' (2016) PROCESS bootstrapping command with 5,000 iterations (model 1). A post-hoc power analysis showed that Cohen's $\mathrm{f}^{2}$ effect size $(0.16$; $R^{2}=0.14$ ) for the moderation model with three pedictors yielded sufficient power $(1-\beta=0.80)$. The low perceived choice manipulation significantly decreased guilt $(b=-0.84$, $S E=0.31, t=-2.71, p=0.009 ; 95 \%$ CI [-1.45, -0.22]), and this effect was qualified by a marginally significant interaction $(b=0.46, S E=0.27, t=1.74, p=0.087 ; 95 \%$ CI $[-0.07$, $0.99])$. The interaction effect size $\left(\Delta R^{2}=0.04\right)$ was 0.04 (Cohen's $\mathrm{f}^{2}$ ), indicating the small-sized effect. As shown in Fig. 5, for participants who suppressed emotions less frequently, those who were assigned to the low ( $v s$. high) choice condition reported less collective guilt $(b=-1.38, S E=0.44$, $t=-3.14, p=0.003 ; 95 \%$ CI [-2.25, -0.50]). For participants who suppressed emotions more frequently, the experimental manipulation did not affect collective guilt $(b=-0.29$, $S E=0.44, t=-0.67, p=0.506 ; 95 \%$ CI [-1.17, 0.58]).
Fig. 6 Direct and indirect effects of system justification on collective action as a function of expressive suppression in Study 3

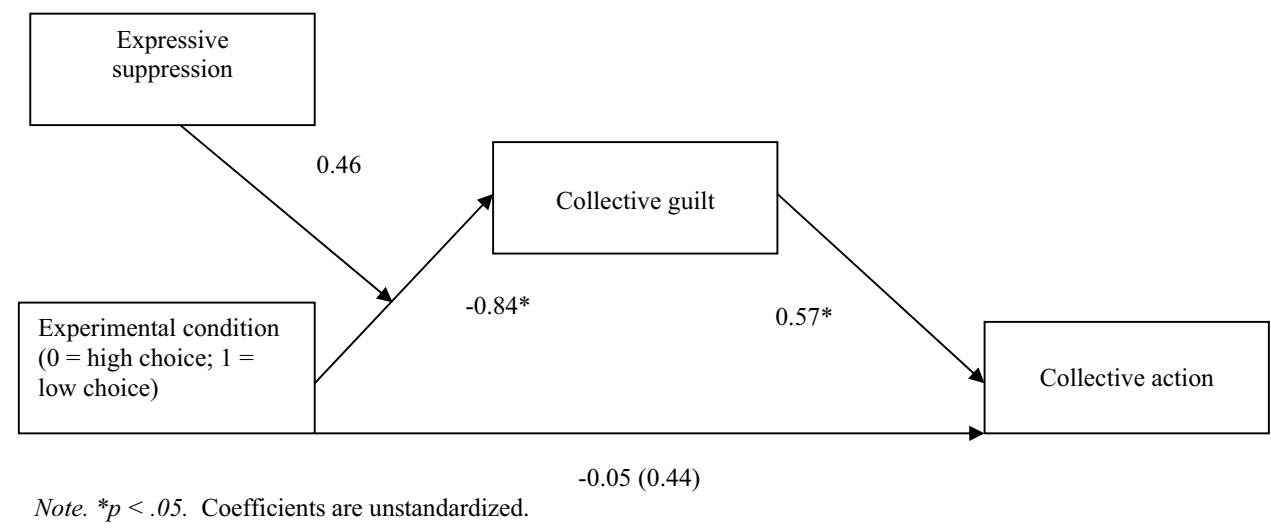


We then proceeded to test a moderated mediation model in which collective guilt mediated the relationship between the experimental manipulation and collective action as a function of expressive suppression, using Hayes's (2016) PROCESS bootstrapping command with 5,000 iterations (model 7). The moderated mediation model was significant (index of moderated mediation $=0.26, S E=0.12,95 \%$ CI $[0.06,0.54]$; see Fig. 6). In line with our hypothesis, for participants who tended to use expressive suppression less frequently, the low perceived choice message decreased collective guilt, thereby undermining willingness to engage in collective action $(b=-0.78, S E=0.22,95 \%$ CI $[-1.29$, $-0.39])$. However, for those who tended to use expressive suppression more frequently, collective guilt did not mediate the effect of the manipulation on collective action $(b=-0.17$, $S E=0.25,95 \%$ CI $[-0.72,0.28])$.

\section{Discussion}

In Study 3, we conceptually replicated and extended the results of the first two studies in the context of collective guilt. We, therefore, demonstrated that our model was applicable to another type of collective action, namely protest against transgressions committed on behalf of the nation. We found that experimentally altering system justification tendencies influenced willingness to engage in collective action through collective guilt for people who tend to use expressive suppression infrequently, but not for people who tend to use expressive suppression frequently. Although we obtained support for the proposed moderated mediation model, the manipulation did not significantly affect collective action intentions. ${ }^{7}$ Because some analyses were slightly underpowered, these results should be interpreted cautiously.

Another interpretational ambiguity arises from the possibility that expressive suppression in the political domain and reluctance to participate in collective action might be two sides of the same coin. However, the two concepts can be differentiated. Expressive suppression involves inhibiting the overt display of emotions (Gross \& Levenson, 1993), whereas collective action depends upon group identification, perceptions of injustice, and shared behaviors aimed at supporting or challenging the social system (Becker, 2012; Turner-Zwinkels \& van Zomeren, 2020). Thus, expressive suppression targets the expression of emotions, whereas

\footnotetext{
7 Although the main effect of the experimental manipulation on collective action was not significant, we did conduct a moderated mediation model. According to Hayes (2009), it is not necessary to observe "a significant total effect before proceeding with tests of indirect effects. A failure to test for indirect effects in the absence of a total effect can lead to you miss some potentially interesting, important, or useful mechanisms by which X exerts some kind of effect on Y" (pp. 414-415; see also Hayes, 2018, p. 117).
}

support for collective action focuses on behavior. At the same time, it is true that emotions are clearly capable of motivating collective action (e.g., Van Zomeren et al., 2004). In any case, we observed in Studies 1-3 that individual differences in expressive suppression and support for collective action were either uncorrelated or weakly correlated with one another (in Study 1). Although this study focused on the role of expressive suppression, we did not manipulate it directly, so it is not possible to address the causal role of expressive suppression in attenuating the association between system justification and negative emotion. Therefore, we manipulated both system justification and expressive suppression (vs. emotion expression) in an experimental design in Study 4.

\section{Study 4}

In Study 4, we investigated whether system justification and expressive suppression jointly affect anger and support for collective action. To this end, we sought to manipulate both variables independently. The experiment was conducted in the United States and focused on governmental tracking of citizens' private phone calls, e-mails, web-browsing activities, and social media posts. We selected this context because it offered an opportunity to induce system-level anger and collective action intentions, insofar as many acts of surveillance violate Americans' right to privacy and some may be illegal (e.g., Fisher, 2019; Toomey, 2018).

We hypothesized that for participants assigned to the emotion expression condition, those in the low system justification condition would report more anger than those in the high system justification condition. However, for participants assigned to the expressive suppression condition, we hypothesized that the dampening effect of system justification on anger would be attenuated. Likewise, we hypothesized that anger would mediate the effect of system justification on willingness to participate in collective action, but only in the absence of expressive suppression. We preregistered this study. ${ }^{8}$

\section{Participants and design}

Previous research on emotion regulation in context of American politics produced a small to moderate effect size (e.g., Hasson et al., 2018; Cohen's $\mathrm{f}=0.19)$. We used this estimate to determine our sample size. ${ }^{9}$ Detecting this effect size at

\footnotetext{
${ }^{8}$ As in the previous studies, we collected additional measures for exploratory purposes, including measures of emotion regulation difficulty, attitudes toward surveillance, expressive suppression, and the direction of emotion regulation. These are listed in the pre-registration document, available at https://aspredicted.org/see_one.php.

${ }^{9}$ Although an a priori power analysis might have been more appropriate, we based our sample size on previous research by Hasson et al. (2018) conducted in the U.S. with similar variables pertaining to emotion regulation and political attitudes.
} 
the power of 0.80 at the conventional level of alpha (0.05) in ANOVA via Gpower generated a minimum requirement of 220 participants. We oversampled to ensure that even after data exclusions, as described below, the study would possess adequate power. We therefore decided to terminate data collection after reaching 300 participations. This procedure produced an original sample of 307 U.S. adults. Participants were excluded for the following reasons: failing attention checks $(n=56)^{10}$; admitting that they completed the study carelessly $(n=3)$; and taking more than twice the median response time ( $M d n=17.23 \mathrm{~min}, M=19.45, S D=9.95)$ to answering the questionnaire $(n=17)$. After these data exclusions, the remaining sample consisted of 231 participants.

Although the platform we used, Prolific Academic, offers a highly diverse population in terms of ethnicity and geographical region (Peer, Samat, Brandimarte, \& Acquisti, 2017), in terms of politics, our sample was heavily skewed towards the Democratic Party, with 194 (84.2\%) participants identifying as Democrats, $25(10.8 \%)$ as Republicans, and $12(5.2 \%)$ reporting other party preferences. We decided to analyze only data from Democrats for two reasons. First, as noted above, and very few Republicans completed our study. Second, our pilot study (see Footnote 11) confirmed that Democrats were much less supportive of mass surveillance than Republicans. The final sample therefore included 194 Democratic participants $(126$ females, Mage $=29.55$, $S D$ age $=11.42$, range $=17-80$ ). All of these participants declared their nationality to be American, their residency to be in the United States, and their first language to be English.

The data were collected in April 2020 through Prolific Academic in return for approximately $\$ 2.60$. Participants were randomly assigned to one of four conditions according to a 2 (emotion regulation: emotion expression vs. expressive suppression) $\times 2$ (system justification: low vs. high) factorial design.

\section{Procedure}

Participants were invited to take part in two ostensibly unrelated studies that were said to be administered together because of budgetary constraints. In "the first study", participants were assigned to a low or high system justification condition. The manipulation, which required participants to think about the ways in which things are organized legally, socially, and economically in the U.S, was adapted from Jost

\footnotetext{
10 Three attention check questions were used. One question was an instructional attention check (IMCs; Oppenheimer, Meyvis, \& Davidenko, 2009), and two questions were related to the video stimuli contents (e.g., "What is the name of the institution that is accused of illegal surveillance?" and "What is the name of the movement against surveillance that is mentioned at the end of the video?"). Participants who failed on the instructional attention check question and one of two reading check questions were excluded from the analysis.
}

et al. (2012) to fit the study context. In the low system justification condition, participants were asked to write about things that function badly in the U.S. system, whereas in the high system justification condition, participants were asked to write about things that function well in the U.S. system (see Appendix). After responding to one of the system-level prompts, participants answered three manipulation check items on a 9-point Likert-type scale $(1=$ Strongly disagree; $9=$ Strongly agree; Chronbach's $\alpha=0.95$ ): (1) "I think the way the American system works is fair", (2) "I like the way things are organized and arranged legally, socially, and economically in the U.S.", and (3) "I am satisfied with the way things are organized or arranged legally, socially, or economically in the U.S."

Next, participants were told that there have been a number of troubling incidents in which the private communications of ordinary Americans have been monitored by the government in recent years (see Appendix). They were informed that they would watch a video about the National Security Agency's mass surveillance of U.S. citizens. Participants were then randomly assigned to either an expressive suppression or an emotion expression condition (see Burns et al., 2007; Gross, 1998). Participants in the expressive suppression condition were instructed not to let their feelings show while watching the video clip. In contrast, participants in the emotion expression condition were instructed to express their feelings freely and openly (see Appendix). Next, participants watched the anger-inducing video clip, which was selected on the basis of a pilot study. Participants were instructed to watch the video once and in full and were then asked to respond to two attention check items about the content of the video. ${ }^{11}$

After watching the video, participants completed two items to check on the manipulation of expressive suppression ("I hid my emotions during the video", and "During the video, I tried not to show my feelings", $r=0.85, p<0.001$ )

\footnotetext{
${ }_{11}$ Using the Prolific platform, we exposed 126 participants (75 females, 51 males, Mage $=38.63$, SDage $=13.50$, range $=18-80 ; 31$ Republicans, 95 Democrats) to three videos about surveillance in the U.S. and selected the the one that aroused the most anger. First, participants watched each video and rated their emotions in response to the government's surveillance (e.g., anger; rage, unease, fury, frustration, annoyance) on a scale of 1 (Not at all) to $9($ A great deal). Next, participants answered two questions: "I approve the government's collection of personal privacy data (e.g., phone calls, internet data) of the Americans" and "I think monitoring the private communication of American citizens by the government is unacceptable" (reverse) $(1=$ Strongly disagree $; 7=$ Strongly agree $; r=0.65, p<.001)$. One sample $t$-tests were used to compare anger-related emotions with the scale midpoint (5). Results revealed that Democrats scored significantly above the midpoint in terms of anger $(M=5.85, S D=2.11$, $t(94)=3.94, p<.001)$, but Republicans did not $(M=5.65 ; S D=2.82$, $t(30)=1.27, p=.213)$. Democrats also reported lower level of support for mass surveillance $(M=1.71, S D=1.08)$ than Republicans $(M=2.40, S D=1.47), t(41.04)=2.43, p=.019$.
} 
Table 4 Descriptive statistics, including correlations among major study variables in study 4

\begin{tabular}{|c|c|c|c|c|c|c|}
\hline & 1 & 2 & 3 & 4 & 5 & $\begin{array}{l}M \\
(S D)\end{array}$ \\
\hline $\begin{array}{l}\text { 1. Expressive suppression condition } \\
(0=\text { emotion expression; } 1= \\
\text { expressive suppression })\end{array}$ & - & 0.07 & -0.12 & -0.09 & 0.12 & $\begin{array}{l}0.52 \\
(0.50)\end{array}$ \\
\hline $\begin{array}{l}\text { 2. System justification condition } \\
(0=\text { low system justification; } \\
1=\text { high system justification })\end{array}$ & & - & -0.12 & -0.11 & $0.16^{*}$ & $\begin{array}{l}0.47 \\
(0.50)\end{array}$ \\
\hline 3. System-based anger & & & - & $0.52 *$ & $-0.15^{*}$ & $\begin{array}{l}5.41 \\
(1.97)\end{array}$ \\
\hline 4. Collective action & & & & - & $-0.20 *$ & $\begin{array}{l}4.22 \\
(2.07)\end{array}$ \\
\hline 5. General system justification scale & & & & & - & $\begin{array}{l}3.16 \\
(1.53)\end{array}$ \\
\hline
\end{tabular}

Note. $N=194, * p<.05$ and two items checking on the perceived success of emotion expression ("During the video, I tried to express my feelings openly and freely", and "I showed my emotions during the video", $r=.0 .89, p<0.001)$. Manipulation check measures were rated on a 9-point Likert type scale $(1=$ Strongly Disagree $; 9=$ Strongly agree $)$. For exploratory purposes, participants also completed the general system justification scale at the end of the study.

\section{Measures}

\section{Video stimuli}

Participants watched a short video (3 min. 21 secs) about mass surveillance targeting U.S. citizens. The video clip was taken from a slightly longer video (see https://rally. stopwatching.us/) published on StopWatching.us, which is a coalition of more than 100 public advocacy organizations and companies that are calling upon the U.S. Congress to investigate the NSA's spying programs. We edited the clip to remove expressions of fear to focus exclusively on the emotion of anger.

\section{Emotions}

Participants rated their current level of anger toward the government's surveillance (e.g., anger, rage, unease, fury, frustration, and annoyance; Cronbach's $\alpha=0.93$ ). Responses were given on a 9 -point scale $(1=$ Not at all; $9=A$ great deal).

\section{Collective action intentions}

We used 12 items to capture willingness to participate in collective action against surveillance in the U.S. Items mentioned attending meetings or workshops; raising issues in groups or organizations; attending demonstrations, protests, or rallies; contacting an elected official; helping to organize a rally or demonstration; spending time on a fundraiser, doing something with other people to voice concerns; demanding an explanation from an elected official; taking part in a legal protest against surveillance; and volunteering in a civil organization (Cronbach's $\alpha=0.96$ ). Responses were given on a 9 -point scale $(1=$ Not willing at all; $9=$ Very much willing).

\section{General System Justification}

Although we used an experimental manipulation of system justification, participants again completed the General System Justification Scale (Kay \& Jost, 2003; Cronbach's $\alpha=0.91$ ), with responses provided on a 9-point Likert-type scale $(1=$ Strongly disagree $; 9=$ Strongly agree $)$.

\section{Results}

Separate $2 \times 2$ analyses of variance (ANOVAs) on each manipulation check revealed effective system justification and expressive suppression manipulations. With respect to system justification, there was a main effect of the system justification manipulation, $F(1,190)=9.34, p=0.003$, $\eta_{p}{ }^{2}=0.05$, such that participants in the high system justification condition reported higer agreement with system justification manipulation check questions $(M=4.08$, $S D=2.03)$ than those in the low system justification condition $(M=3.24, S D=1.76)$. With respect to emotion suppression, there were main effects of the emotion suppression manipulation, $F(1,190)=644.69, p<0.001$, $\eta_{p}{ }^{2}=0.77$, such that participants in the expressive suppression condition $(M=7.72, S D=1.60)$ reported suppressing more than participants in the emotion expression $(M=2.17$, $S D=1.40)$. Likewise, participants in the suppression condition $(M=1.62, S D=0.94)$ reported expressing less than participants in the expression condition $(M=6.81, S D=1.88)$, 
Fig. 7 Interaction between scores on the general system justification scale and expressive suppression in Study 4

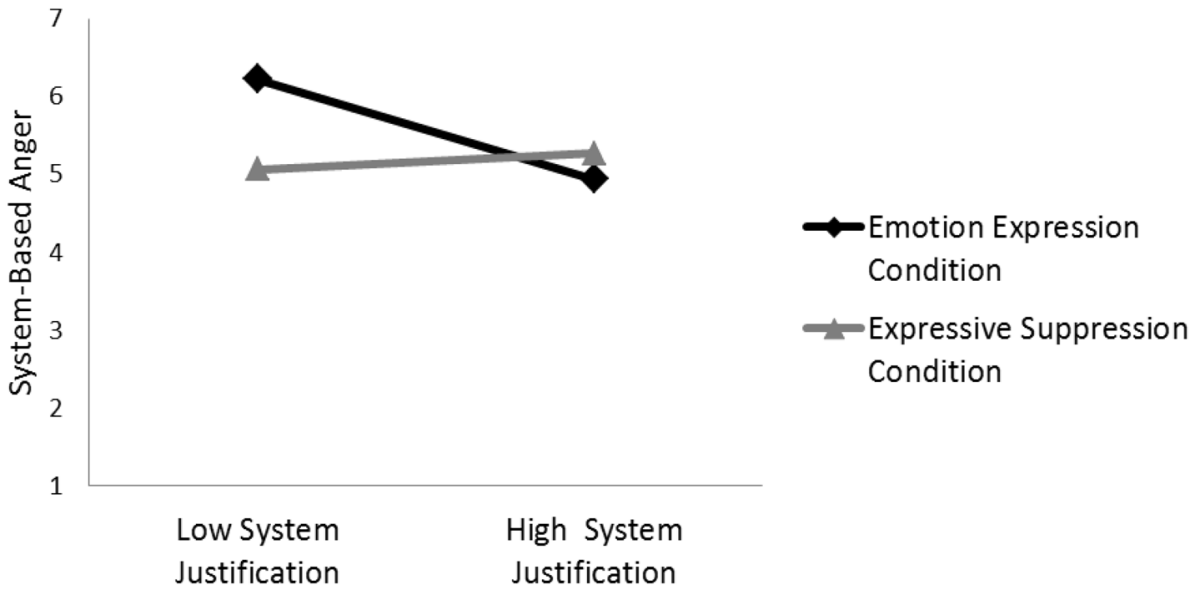

$F(1,190)=596.42, p<0.001, \eta_{p}{ }^{2}=0.76$. No interaction effects were significant (system justification check: $F(1$, 190) $=0.40, p=0.527, \eta_{p}{ }^{2}=0.002$; expressive suppression check: $F(1,190)=0.15, p=0.697, \eta_{p}{ }^{2}=0.001$; emotion expression check $\left.=F(1,190)=3.01, p=0.084, \eta_{p}{ }^{2}=0.02\right)$. Table 4 shows correlations and other descriptive statistics. These correlations indicated that emotion expression (vs. expressive suppression) was not significantly related to collective action intention.

\section{Analysis with system justification as a manipulated variable}

We tested the moderating effect of expressive suppression on the relationship between manipulation of system justification and anger, using Hayes's (2019) PROCESS bootstrapping command with 5.000 iterations (model 1). Results demonstrated that neither system justification $(b=-0.42, S E=0.28$, $t=-1.50, p=0.136,95 \%$ CI $[-0.98,0.13])$ nor expressive suppression $(b=-0.45, S E=0.28, t=-1.59, p=0.113,95 \%$ CI $[-1.01,0.11])$ significantly predicted anger. Contrary to our hypothesis, the interaction effect was not significant $(b=0.12, S E=0.57, t=0.20, p=0.840,95 \%$ CI $[-1.00$, 1.23]). ${ }^{12}$

\section{Analysis with system justification as a measured variable}

Because the system justification manipulation failed to affect anger in the hypothesized ways, we conducted a parallel exploratory analysis with scores on the general system

\footnotetext{
12 We also conducted 2 (emotion expression vs expressive suppression) $\times 2$ (low vs high system justification) analyses of variance (ANOVA) on anger. Results demonstrated that there was not a main effect of the system justification manipulation, $F(1,190)=2.26$, $p=.135, \eta_{p}{ }^{2}=0.01$. Likewise, neither tha main effect of expressive suppression $\left(F(1,190)=2.50, p=.116, \eta_{p}{ }^{2}=0.01\right)$ nor the interaction $\left(F(1,190)=0.04, p=.840, \eta_{p}{ }^{2}=0.000\right)$ were significant.
}

justification scale. ${ }^{13}$ Specifically, we tested the moderating effect of the expressive suppression manipulation on the relationship between system justification and anger. A post-hoc power analysis showed that Cohen's $\mathrm{f}^{2}$ effect size $\left(0.08 ; R^{2}=0.07\right)$ for the moderation model with three pedictors yielded sufficient power $(1-\beta=0.92)$. In this analysis, system justification was marginally associated with anger in the predicted direction $(b=-0.17, S E=0.09$, $t=-1.85, p=0.067 ; 95 \%$ CI $[-0.35,0.01])$, but the association between expressive suppression and anger was not significant $(b=-0.41, S E=0.28, t=-1.49, p=0.137 ; 95 \%$ CI [-0.96, 0.13]). The interaction, however, was significant $(b=0.49, S E=0.18, t=2.69, p=0.008 ; 95 \%$ CI $[0.13$, $0.85])$. In the emotional expression condition participants who were lower (vs. higher) in system justification reported more anger $(b=-0.42, S E=0.13, t=-3.24, p=0.001 ; 95 \%$ CI [-0.68, -0.17]). In the expressive suppression condition, on the other hand, system justification was unrelated to anger $(b=0.07, S E=0.13, t=0.54, p=0.588 ; 95 \%$ CI $[-0.18,0.32]$ (see Fig. 7). Here, sensitivity power analysis for the interaction term (multiple regression: $R^{2}$ increase) using 0.80 as a threshold yielded an effect size of 0.04 , indicating that the minimal detectable effect was a small-sized effect. We observed that the interaction effect size $\left(\Delta R^{2}=0.04\right)$ was 0.04 (Cohen's $\mathrm{f}^{2}$ ), reflecting a small-sized effect.

\footnotetext{
13 To determine whether the system justification manipulation affected the measure of system justification, we conducted a 2 (emotion expression vs expressive suppression condition) $\times 2$ (low vs high system justification condition) analysis of variance (ANOVA). Results revealed that there was a main effect of the system justification manipulation, $F(1,190)=4.70, p=.031, \eta_{p}^{2}=0.02$, such that participants assigned to the high system justification condition scored higher on general system justification $(M=3.42, S D=1.75)$ than those assigned to the low system justification condition $(M=2.93$, $S D=1.25)$. Neither the main effect of expressive suppression condition $\left(F(1,190)=2.29, p=.132, \eta_{p}{ }^{2}=0.01\right)$ nor the two-way interaction $\left(F(1,190)=0.135, p=.713, \eta_{p}{ }^{2}=0.001\right)$ were significant.
} 
Fig. 8 Direct and indirect effects of system justification on collective action as a function of expressive suppression in Study 4

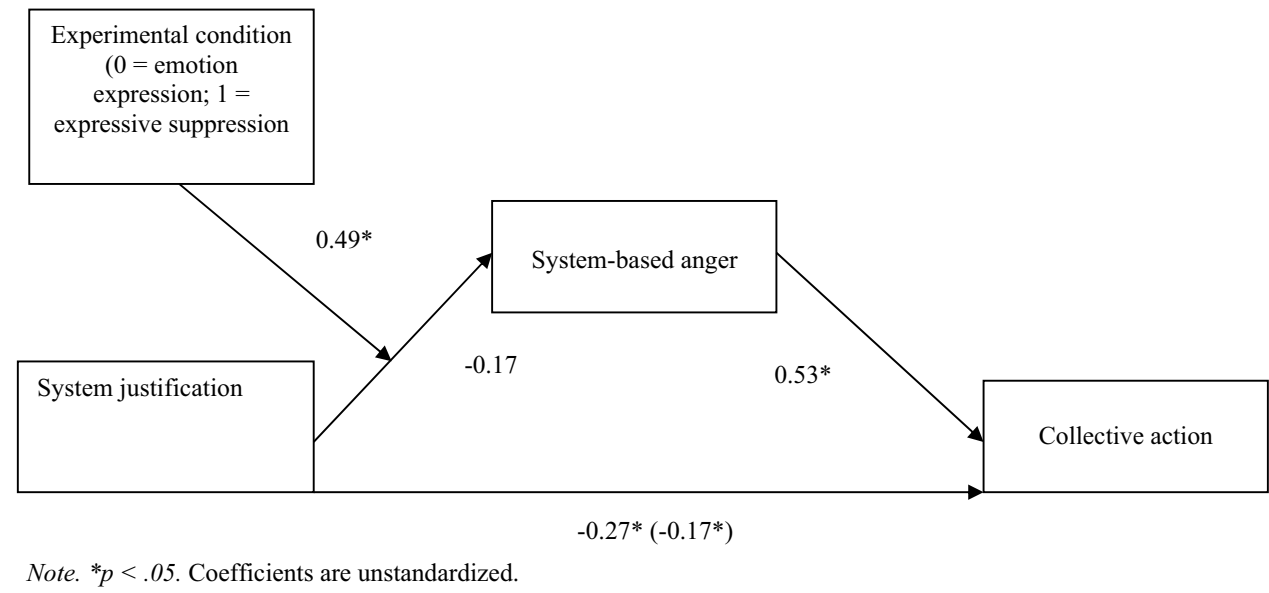

Next, we examined the moderated mediation model in which anger mediated the relationship between scores on the general system justification scale and collective action as a function of expressive suppression manipulation, using Hayes's (2019) PROCESS bootstrapping command with 5,000 iterations (model 7). The moderated mediation model was significant (index of moderated mediation $=0.26$, $S E=0.10,95 \%$ CI $[0.05,0.46]$; see Fig. 8). In the emotional expression condition, anger mediated the negative association between system justification and willingness to engage in collective action $(b=-0.22, S E=0.07,95 \%$ CI $[-0.38$, $-0.09])$. This was not the case in the expressive suppression condition $(b=0.04, S E=0.08,95 \%$ CI $[-0.14,0.17])$.

\section{Discussion}

In Study 4, the results partially replicated the findings of the previous studies. We found no support for the hypothesized interaction between manipulated expressive suppression and system justification as a manipulated variable. However, the hypothesis was upheld when we tested it using scores on the general system justification scale. In the emotional expression condition, low system-justifiers reported more anger and, consequently, more support for collective action, in comparison with high system-justifiers. In the expressive suppression condition, however, there were no differences between low and high system-justifiers.

There may be several reasons why we did not obtain a significant interaction between system justification and expressive suppression as manipulated variables. First, it is possible that the manipulations, both of which were textbased, were too complicated or mentally taxing to work in tandem as we had expected. Second, it might be relevant that the study was conducted during the coronavirus pandemic. Insofar as the pandemic presumably made inequality and system-related problems (with the health care and economic systems) more salient in the U.S., it is possible that the induction of the high system justification mindset was too weak to be sustained throughout the experiment. Third, it is possible that other individual differences, such as political orientation or party identification, might have affected the efficacy of the system justification manipulation in our sample. We did not measure the strength of partisanship in this study. However, we know from previous research that liberals and Democrats tend to score lower than conservatives and Republicans on system justification (e.g., Azevedo et al., 2017). Thus, it is conceivable that liberals and strongly identified Democrats might have found it difficult to maintain a high system justification mindset, especially during the Trump presidency and coronavirus crisis.

Importantly, however, our secondary analysis did yield a significant interaction between expressive suppression and scores on the general system justification scale. Thus, when system justification was measured as an individual difference variable, the predicted pattern was obtained.

\section{General discussion}

Previous research has found that justifying the existing social system and its authorities undermines support for collective action, in part, by decreasing negative emotions (e.g., Becker \& Wright, 2011; Jost et al., 2012; Wakslak et al., 2007). High system-justifiers tend to express fewer negative emotions such as anger and guilt and are less likely to engage in system-challenging collective action, in comparison with low system-justifiers. At the same time, very few citizens actually participate in collective action (Jost et al., 2017), so there must also be non-ideological reasons why even low system-justifiers eschew collective action. Building on theory and research on emotion regulation, we proposed that the link between system justification and collective action should depend upon the ways in which people regulate their emotions. 
In the four studies reported here, we observed that people who question the societal status quo report more negative emotions and support for system-challenging collective action-unless, that is, they are disposed to engage in expressive suppression of their emotions directed at the social system. Presumably, this is because protesting not only requires experiencing certain emotions but also being willing to express those emotions in public. To the extent that individuals inhibit their emotional expressionsespecially the expression of negative emotions directed at the social system-they are unlikely to participate in collective action aimed at improving the status quo, even if they disapprove of the way things are. In support of this hypothesis, we observed that expressive suppression moderated the effect of system justification on system-based anger and collective guilt, thereby undermining support for system-challenging collective action. We obtained evidence from both correlational (Study 1) and experimental (Studies 2-4) designs in three quite different countries (Israel, Turkey, and the U.S.).

From a broader theoretical perspective, understanding the interactive effects of system justification and emotion regulation on system-based anger, collective guilt, and collective action should help to integrate seemingly disparate research programs on emotions and political psychology (see also Jost et al., 2017). The current study extends previous work on system justification, emotion regulation, and collective action by suggesting that expressive suppression serves as an emotional brake on the push for social change. It follows that activist causes would benefit from social norms encouraging the open, uncensored expression of system-based emotion.

\section{Implications for system justification theory}

The present findings highlight the importance of considering emotion regulation strategies when examining the link between system justification and collective action. Although past research explored the affective consequences of system justification (e.g., Wakslak et al., 2007), the possibility that these effects would be attenuated by emotion regulation strategies had not been previously considered. Hence, the current program of research represents an important first step in integrating research lines on system justification and emotion regulation.

Our findings indicate that low system-justifiers report more anger about the system and more collective guilt about injustice, but only if they are disinclined to use the emotion regulation strategy of expressive suppression. We found that system justification was unrelated to system-based anger and collective guilt for people who frequently use expressive suppression. This finding is important because it could help to explain why some people who criticize the social system are unwilling to do much to change it.

\section{Implications for emotion regulation and collective action}

Our work also has clear implications for the study of emotion regulation. Previous research has shown that expressive suppression may be detrimental to the individual's health and the quality of close interpersonal relationships (Gross, 2002). Our work suggests that expressive suppression may have harmful consequences not only for individuals and dyads but also for society as a whole, insofar as it is associated with a reluctance to support social change. Our findings are consistent with a previous demonstration that the inhibition of anger expression in response to discrimination decreased support for collective action (Gill \& Matheson, 2006). They are also highly consistent with a previous demonstration that using the strategy of cognitive reappraisal reduces one's motivation to engage in political action (Ford et al., 2018). As in this earlier study, we focused on social psychological processes that decrease the likelihood of engaging in protest behavior. Because emotion expression is, historically speaking, necessary for the attainment of freedom and equality, inhibiting emotion expression may hinder the motivation for social change even among those who are most likely to support it.

Expressing negative emotions toward authority figures almost surely brings certain social and material costs, such as the risk of losing one's job or social status-especially in more authoritarian, less democratic social contexts (see Bergman, Langhout, Palmieri, Cortina, \& Fitzgerald, 2002). Along similar lines, the fear of participating in collective action blunts the effect of anger in response to unequal treatment (Miller et al., 2009). In certain social contexts, expressive suppression is likely to maintain social harmony at the expense of social change (Kitayama et al., 2006).

Our findings underscore the utility of a contextual approach to emotion regulation, which suggests that contextual variables and the goals of individuals affect the choice and implementation of various emotion regulation strategies (Aldao, 2013; Aldao \& Tull, 2015; Thompson, 1994). Therefore, emotion regulation strategies used in one context may not be appropriate in another context (Hughes \& Gullone, 2011). Our research focused on emotion regulation in specific sociopolitical domains rather than emotion regulation in general (see also Burić et al., 2016; Halperin \& Gross, 2011; Hughes \& Gullone, 2011 for emotion regulation in specific domains). Research on emotion regulation in the socio-political domain focuses on the link between emotion regulation strategies and political attitudes and behaviors (e.g., Gross, Halperin, \& Porat, 2013; for a review, see Ford \& Feinberg, 2020). Our findings are in line with 
a multidimensional, context-sensitive approach to the connection between ideological factors and both automatic and deliberative processes of emotion regulation (Pliskin et al., 2020; Shnabel \& Ullrich, 2016). According to this approach, considering individuals' ideological contexts when studying emotional reactions can help us distinguish automatic reactions from socio-political ideology-driven deliberative reactions. We showed that expressive suppression implemented in particular socio-political contexts moderates the relationship between emotional processes and socio-political outcomes.

\section{Limitations and future directions}

The present set of studies has a number of clear limitations. First, statistical power was low for a number of significance tests conducted in Studies 1-3. These results should be interpreted with caution, but it is noteworthy that we obtained fairly consistent support across studies for the role of expressive suppression in moderating the association between system justification and anger. However, it is true that in Study 3 there was a significant indirect effect without a significant direct effect, and in Study 4 the hypothesized interaction between expressive suppression and system justification as a manipulated variable was not significant. Future research would do well to consider other manipulations of system justification and to make use of larger sample sizes that provide greater statistical power. A second limitation of our research program is that we measured self-reported willingness to participate in collective action rather than actual participation. Future studies should determine whether the effects we have observed with respect to behavioral intentions apply to actual behavior as well. A third limitation is that we cannot explain precisely why some low system-justifiers were inclined to use expressive suppression of system-based emotion. One possibility is that they sought to conceal their emotions in an effort to avoid social reproach. From the standpoint of social change, it would be useful to have a better understanding of the psychological mechanisms underlying the use of expressive suppression strategies, especially in the case of low system-justifiers.

Finally, it would be useful in future research to develop a deeper understanding of the social consequences of emotional suppression within the group. Given that emotions communicate meaningful information to others (Buck, 1984), it is possible that the suppression of negative emotions toward the social system conveys tacit messages to other members of the ingroup. The suppression of anger or collective guilt, for instance, may signal that authority figures are fair, right, and legitimate, and thus that social change is unnecessary or unjustifiable. It is also conceivable that, in some contexts, expressing system-based anger or collective guilt would be considered to be socially inappropriate and may even elicit social sanctions. By exploring the interplay between expressive suppression and system justification processes, the present investigation points to several new avenues for understanding - and perhaps overcoming - the emotional obstacles to the attainment of social change (see also Jost, 2020).

\section{Conclusion}

The present research program illustrates the value of taking into account emotion regulation processes when analyzing the connection between system justification and protest activity. Collective action, it would appear, depends not only on emotional experiences per se but also on the ways in which people deal with and manage their emotions. Work of this type, therefore, has the potential to inform practical interventions designed to increase social justice in society by motivating participation in collective action. If expressive suppression is an obstacle to social change-at least for some people, it follows that the mere expression of systembased emotion is itself an act of clear political significance.

Supplementary Information The online version contains supplementary material available at https://doi.org/10.1007/s11031-021-09883-5.

Acknowledgements We thank Racheli Cohen for their assistance with data collection as well as Arda Aksoy and Fatih Bayrak for their help with preparing the video stimuli in Study 4.

Funding This work was supported in part by the European Research Council under Grant \# 335607 to Eran Halperin and a National/Binational Science Foundation Award \# BCS-1627691 to Eran Halperin and John T. Jost.

Data Availability We used existing datasets to test our hypothesis in Studies 1 and 2. These datasets were also used to test different hypotheses in other research. We collected new data for Studies 3 and 4. We designed Study 3 to address the study hypothesis as well as other hypotheses not directly related to the research program reported here. We designed Study 4 specifically to address our key hypothesis. This study was preregistered: https://aspredicted.org/see_one.php. The data that support the findings of these studies are available from the corresponding author upon request.

\section{Declarations}

Conflict of interest All authors declare that they have no conflict of interest.

Ethical approval All procedures performed in studies involving human participants were in accordance with the ethical standards of the institutional and/or national research committee and with the 1964 Helsinki declaration and its later amendments or comparable ethical standards.

Informed consent Informed consent was obtained from all participants included in the studies. 


\section{References}

Abu Hein, F., Qouta, S., Thabet, A. A., \& El Sarraj, E. (1993). Trauma and mental health of children in Gaza. British Medical Journal, 306, 1130-1131. https://doi.org/10.1136/bmj.306.6885.1130-c.

Akdeniz, Y., \& Altıparmak, K. (2018). Turkey: Freedom of expression in jeopardy violations of the rights of authors, publishers and academics under the state of emergency. Retrieved from https:// www.englishpen.org/wp-content/uploads/2018/03/Turkey_Freed om_of_Expression_in_Jeopardy_ENG.pdf.

Aldao, A. (2013). The future of emotion regulation research: Capturing context. Perspectives on Psychological Science, 8, 155-172. https://doi.org/10.1177/1745691612459518.

Aldao, A., \& Tull, M. T. (2015). Putting emotion regulation in context. Current Opinion in Psychology, 3, 100-107. https://doi.org/10. 1016/j.copsyc.2015.03.022.

Alicke, M. D. (2000). Culpable control and the psychology of blame. Psychological Bulletin, 126, 556-574. https://doi.org/10.1037/ 0033-2909.126.4.556.

Azevedo, F., Jost, J. T., \& Rothmund, T. (2017). "Making America great again": System justification in the US presidential election of 2016. Translational Issues in Psychological Science, 3, 231-240. https://doi.org/10.1037/tps0000122.

Bahns, A. J., \& Branscombe, N. R. (2011). Effects of legitimizing discrimination against homosexuals on gay bashing. European Journal of Social Psychology, 40, 1-9. https://doi.org/10.1002/ ejsp.784.

Becker, J. C. (2012). Virtual special issue on theory and research on collective action. European Journal of Social Psychology, 42, 19-23. https://doi.org/10.1002/ejsp.1839.

Becker, J. C., \& Wright, S. C. (2011). Yet another dark side of chivalry: Benevolent sexism undermines and hostile sexism motivates collective action for social change. Journal of Personality and Social Psychology, 101, 62-77. https://doi.org/10.1037/a0022 615.

Bergman, M. E., Langhout, R. D., Palmieri, P. A., Cortina, L. M., \& Fitzgerald, L. F. (2002). The (un)reasonableness of reporting: Antecedents and consequences of reporting sexual harassment. Journal of Applied Psychology, 87, 230-242. https://doi.org/10. 1037/0021-9010.87.2.230.

Borders, A., \& Wiley, S. (2019). Rumination about discrimination mediates the unique association between anger and collective action intentions. Group Processes \& Intergroup Relations. https://doi.org/10.1177/1368430219875214.

Botti, S., \& Iyengar, S. S. (2004). The psychological pleasure and pain of choosing: When people prefer choosing at the cost of subsequent satisfaction. Journal of Personality and Social Psychology, 87, 312-326. https://doi.org/10.1037/0022-3514. 87.3.312

Botti, S., \& McGill, A. L. (2006). When choosing is not deciding: The effect of perceived responsibility on satisfaction. Journal of Consumer Research, 33, 211-219. https://doi.org/10.1086/506302.

Branscombe, N. R., \& Doosje, B. (Eds.). (2004). Collective guilt: International perspectives. Cambridge University Press.

Branscombe, N. R., \& Miron, A. M. (2004). Interpreting the ingroup's negative actions toward another group: Emotional reactions to appraised harm. In L. Z. Tiedens \& C. W. Leach (Eds.), The social life of emotion. (pp. 314-335). Cambridge University Press.

Branscombe, N. R., Slugoski, B., \& Kappen, D. M. (2004). Collective guilt: What it is and what is not. In N. R. Branscombe \& B. Doosje (Eds.), Collective guilt: International perspectives. (pp. 16-34). Cambridge University Press.

Brody, L. R. (2000). The socialization of gender differences in emotional expression: Display rules, infant temperament, and differentiation. In A. H. Fischer (Ed.), Gender and emotion: Social psychological perspectives. (pp. 24-47). Cambridge University Press.

Buck, R. (1984). The communication of emotion. Guilford.

Burić, I., Sorić, I., \& Penezić, Z. (2016). Emotion regulation in academic domain: Development and validation of the academic emotion regulation questionnaire (AERQ). Personality and Individual Differences, 96, 138-147. https://doi.org/10.1016/j. paid.2016.02.074.

Burns, J. W., Quartana, P. J., \& Bruehl, S. (2007). Anger management style moderates effects of emotion suppression during initial stress on pain and cardiovascular responses during subsequent pain-induction. Annals of Behavioral Medicine, 34, 154-165. https://doi.org/10.1007/BF02872670.

Burns, K. C., Isbell, L. M., \& Tyler, J. M. (2008). Suppressing emotions toward stereotyped targets: The impact on willingness to engage in contact. Social Cognition, 26, 276-287. https://doi.org/ 10.1521/soco.2008.26.3.276.

Butler, E. A., \& Gross, J. J. (2004). Hiding feelings in social contexts: Out of sight is not out of mind. P. Philippot \& R. Feldman (Eds.), The regulation of emotion (pp. 101-126). Lawrence Erlbaum Associates.

Butler, E. A., Egloff, B., Wlhelm, F. H., Smith, N. C., Erickson, E. A., \& Gross, J. J. (2003). The social consequences of expressive suppression. Emotion, 3, 48-67. https://doi.org/10.1037/15283542.3.1.48

Chernovsky, E., \& Hunt, C. (2017). Suppression and expression of emotion in social and interpersonal outcomes: A meta-analysis. Emotion, 17, 669-683. https://doi.org/10.1016/j.ijpsycho.2020. 09.013.

CPJ (2012). 2012 prison census: 232 journalists jailed worldwide. Retrieved from https://cpj.org/reports/2012/12/2012-2/.

Doosje, B. E., Branscombe, N. R., Spears, R., \& Manstead, A. S. (1998). Guilty by association: When one's group has a negative history. Journal of Personality and Social Psychology, 75, 872-886. https://doi.org/10.1037/0022-3514.75.4.872.

English, T., \& John, O. P. (2013). Understanding the social effects of emotion regulation: The mediating role of authenticity for individual differences in suppression. Emotion, 13, 314-329. https:// doi.org/10.1037/a0029847.

Faul, F., Erdfelder, E., Buchner, A., \& Lang, A. G. (2009). Statistical power analyses using $\mathrm{G}^{*}$ Power 3.1: Tests for correlation and regression analyses. Behavior Research Methods, 41, 1149-1160. https://doi.org/10.3758/BRM.41.4.1149.

Fanack. com (2015, April 13). Turkey increases pressure on the media. Retrieved from https://fanack.com/turkey/human-rights/ turkey-increases-pressure-on-the-media/.

Fisher, C. (2019, October 8). FISA court: FBI use of NSA's electronic surveillance data was illegal. Engadget. Retrieved from https://www.engadget.com/2019-10-08-fbi-surveillance-viola ted-constitutional

Ford, B. Q., \& Feinberg, M. (2020). Coping with politics The benefits and costs of emotion regulation. Current Opinion in Behavioral Sciences, 34, 123-128. https://doi.org/10.1016/j. cobeha.2020.02.014

Ford, B. Q., Feinberg, M., Lam, P., Mauss, I. B., \& John, O. P. (2018). Using reappraisal to regulate negative emotion after the 2016 US Presidential election: Does emotion regulation Trump political action? Journal of Personality and Social Psychology. https://doi.org/10.1037/pspp0000200.

Frijda, N. H., Kuipers, P., \& ter Schure, E. (1989). Relations among emotion, appraisal, and emotional action readiness. Journal of Personality and Social Psychology, 57, 212-228. https://doi. org/10.1037/0022-3514.57.2.212. 
Gill, R., \& Matheson, K. (2006). Responses to discrimination: The role of emotion and expectations for emotional regulation. Personality and Social Psychology Bulletin, 32, 149-161.

Goudarzi, S., Pliskin, R., Jost, J. T., \& Knowles, E. D. (2020). Economic system justification predicts muted emotional responses to inequality. Nature Communications, 11, 1-9.

Gross, J. J. (1998). Antecedent- and response-focused emotion regulation: Divergent consequences for experience, expression, and physiology. Journal of Personality and Social Psychology, 74, 224-237. https://doi.org/10.1037/0022-3514.74.1.224

Gross, J. J. (2002). Emotion regulation: Affective, cognitive and social consequences. Psychophysiology, 39, 281-291.

Gross, J. J., Halperin, E., \& Porat, R. (2013). Emotion regulation in intractable conflicts. Current Directions in Psychological Science, 22, 423-429. https://doi.org/10.1177/0963721413495871

Gross, J. J. (2014). Emotion regulation: Conceptual and empirical foundations. In J. J. Gross (Ed.), Handbook of emotion regulation. (2nd ed., pp. 3-20). Guilford.

Gross, J. J., \& John, O. P. (2003). Individual differences in two emotion regulation processes: Implications for affect, relationships, and well-being. Journal of Personality and Social Psychology, 85, 348-362. https://doi.org/10.1037/0022-3514.85.2.348

Gross, J. J., \& Levenson, R. W. (1993). Emotional suppression: Physiology, self-report, and expressive behavior. Journal of Personality and Social Psychology, 64, 970-986. https://doi. org/10.1037/0022-3514.64.6.970

Halperin, E. (2016). Emotions in conflict: Inhibitors and facilitators of peace making. Routledge.

Halperin, E., \& Gross, J. J. (2011). Emotion regulation in violent conflict: Reappraisal, hope, and support for humanitarian aid to the opponent in wartime. Cognition \& Emotion, 25, 12281236. https://doi.org/10.1080/02699931.2010.536081.

Harding, J. F., \& Sibley, C. G. (2013). The palliative function of system justification: Concurrent benefits versus longer-term costs to well-being. Social Indicators Research, 113, 401-418. https://doi.org/10.1007/s11205-012-0101-1.

Hasson, Y., Tamir, M., Brahms, K. S., Cohrs, J. C., \& Halperin, E. (2018). Are liberals and conservatives equally motivated to feel empathy toward others? Personality and Social Psychology Bulletin, 44, 1449-1459. https://doi.org/10.1177/01461 67218769867.

Hayes, A. F. (2009). Beyond Baron and Kenny: Statistical mediation analysis in the new millennium. Communication Monographs, 76, 408-420. https://doi.org/10.1080/03637750903310360.

Hayes, A. F. (2016). PROCESS (Version 2.15) [Software]. Retrieved from http://www.processmacro.org/download.html.

Hayes, A. F. (2018). An introduction to mediation, moderation, and conditional process analysis: A regression-based approach. (2nd ed.). Guilford Press.

Hayes, A. F. (2019). PROCESS (Version 3.4) [Software]. Retrieved from http://www.processmacro.org/download.html.

Hensby, A. (2017). Networks of non-participation: Comparing 'supportive', 'unsupportive' and 'undecided'non-participants in the UK student protests against fees and cuts. Sociology, 51, 957-974. https://doi.org/10.1177/0038038515608113.

Hughes, E. K., \& Gullone, E. (2011). Emotion regulation moderates relationships between body image concerns and psychological symptomatology. Body Image, 8, 224-231. https://doi.org/10. 1016/j.bodyim.2011.04.001

Jack, D. C. (2011). Reflections on the silencing the self and its origins. Psychology of Women Quarterly, 35, 523-529. https:// doi.org/10.1177/0361684311414824.

Jack, D. C., \& Dill, D. (1992). The Silencing the Self Scale: Schemas of intimacy associated with depression in women. Psychology of Women Quarterly, 16, 97-106. https://doi.org/10.1111/j. 1471-6402.1992.tb00242.x.
Jost, J. T. (2017). Ideological asymmetries and the essence of political psychology. Political Psychology, 38, 167-208. https://doi. org/10.1111/pops.12407.

Jost, J. T. (2020). A theory of system justification. Harvard University Press.

Jost, J. T., Becker, J., Osborne, D., \& Badaan, V. (2017). Missing in (collective) action: Ideology, system justification, and the motivational antecedents of protest behavior. Current Directions in Psychological Science, 26, 99-108. https://doi.org/10. 1177/0963721417690633.

Jost, J. T., Chaikalis-Petritsis, V., Abrams, D., Sidanius, J., der Toorn, V., \& Bratt, C. (2012). Why men (and women) do and don't rebel: Effects of system justification on willingness to protest. Personality and Social Psychology Bulletin, 38, 197208. https://doi.org/10.1177/0146167211422544.

Jost, J. T., Wakslak, C., \& Tyler, T. R. (2008). System justification theory and the alleviation of emotional distress: Palliative effects of ideology in an arbitrary social hierarchy and in society. In K. Hegtvedt, \& J. Clay-Warner (Eds.), Advances in Group Processes (Vol 25, pp.181-211). Elsevier.

Kay, A. C., Jost, J. T., \& Young, S. (2005). Victim derogation and victim enhancement as alternate to system justification. Psychological Science, 16, 240-246. https://doi.org/10.1111/j. 0956-7976.2005.00810.x

Kay, A. C., \& Jost, J. T. (2003). Complementary justice: Effects of "poor but happy" and "poor but honest" stereotype exemplars on system justification and implicit activation of the justice motive. Journal of Personality and Social Psychology, 85, 823-837. https://doi.org/10.1037/0022-3514.85.5.823

Kay, A. C., Gaucher, D., Peach, J. M., Friesen, J., Laurin, K., Zanna, M., \& P., \& Spencer, S. J. (2009). Inequality, discrimination, and the power of the status quo: Direct evidence for a motivation to view what is as what should be. Journal of Personality and Social Psychology, 97, 421-434. https://doi.org/10.1037/ a0015997

Kitayama, S., Mesquita, B., \& Karasawa, M. (2006). Cultural affordances and emotional experience: Socially engaging and disengaging emotions in Japan and the United States. Journal of Personalityand Social Psychology, 91, 890-903. https://doi.org/ 10.1037/0022-3514.91.5.890.

Klandermans, B., \& Oegema, D. (1987). Potentials, networks, motivations, and barriers: Steps towards participation in social movements. American Sociological Review, 52, 519-531. https://doi. org/10.2307/2095297

Klandermans, B., \& van Stekelenburg, J. (2014). Why people don't participate in collective action. Journal of Civil Society, 10, 341-352. https://doi.org/10.1080/17448689.2014.984974.

Langner, C. A., Epel, E. S., Matthews, K. A., Moskowitz, J. T., \& Adler, N. E. (2012). Social hierarchy and depression: The role of emotion suppression. Journal of Psychology: Interdisciplinary and Applied, 146, 417-436. https://doi.org/10.1080/00223980. 2011.652234.

Laurin, K., Kay, A. C., Proudfoot, D., \& Fitzsimons, G. J. (2013). Responses to restristive policies: Reconciling system justification and psychological reactance. Organizational Behavior and Human Decision Processes, 122, 152-162. https://doi.org/10. 1016/j.obhdp.2013.06.004.

Laurin, K., Shepherd, S., \& Kay, A. C. (2010). Restricted emigration, system ineascapability, and the defense of the status quo: System justifiying consequences of restircted exit opporttunities. Psychological Sceince, 21, 1075-1082. https://doi.org/10.1177/ 0956797610375448.

Leary, M. R., \& Hoyle, R. H. (2009). Handbook of individual differences in social behavior. Guilford Press.

Li, W., Wu, J., \& Kou, Y. (2020). System justification enhances life satisfaction of high-and low-status people in China. Social 
Psychological and Personality Science, 11, 588-596. https:// doi.org/10.1177/1948550619866182.

Liviatan, I., \& Jost, J. T. (2014). A social-cognitive analysis of system justification goal striving. Social Cognition, 32, 95-129. https:// doi.org/10.1521/soco.2014.32.2.95.

Malle, B., Guglielmo, S., \& Monroe, A. (2014). A theory of blame. Psychological Inquiry, 25, 147-186. https://doi.org/10.1080/ 1047840X.2014.877340.

Mallett, R., Huntsinger, J. R., Sinclair, S., \& Swim, J. (2008). Seeing through their eyes: When majority group members take collective action on behalf of an outgroup. Group Processes \& Intergroup Relations, 11, 451-470. https://doi.org/10.1177/13684 30208095400.

Matsumoto, D., Yoo, S. H., Nakagawa, S., Anguas-Wong, A. M., Arriola, M., Bauer, L. M., et al. (2008). Culture, emotion regulation, and adjustment. Journal of Personality and Social Psychology, 94, 925-937. https://doi.org/10.1037/0022-3514.94.6.925.

Miller, D., Cronin, T., Garcia, A., \& Branscombe, N. (2009). The relative impact of anger and efficacy on collective action is affected by feelings of fear. Group Process and Intergroup Relations, 12, 445-462. https://doi.org/10.1177/1368430209105046.

Miron, A. M., Branscombe, N. R., \& Schmitt, M. T. (2006). Collective guilt as distress over illegitimate ingroup advantage. Group Processes and Intergroup Relations, 9, 163-180. https://doi.org/ 10.1177/1368430206062075.

Moors, A., Ellsworth, P. C., Scherer, K. R., \& Frijda, N. H. (2013). Appraisal theories of emotion: State of the art and future development. Emotion Review, 5, 119-124. https://doi.org/10.1177/ 1754073912468165.

Morgan, G. S., \& Chan, W. Y. (2016). Different paths to protest: Predictors of collective action in the Occupy Movement. Journal of Applied Social Psychology, 46, 565-582. https://doi.org/10. 1111/jasp.12386.

Napier, J. L., Bettinsoli, M. L., \& Suppes, A. (2020). The palliative function of system-justifying ideologies. Current Opinion in Behavioral Sciences, 34, 129-134. https://doi.org/10.1016/j. cobeha.2020.03.002.

Oppenheimer, D. M., Meyvis, T., \& Davidenko, N. (2009). Instructional manipulation checks: Detecting satisficing to increase statistical power. Journal of Experimental Social Psychology, 45, 867-872. https://doi.org/10.1016/j.jesp.2009.03.009.

Osborne, D., Jost, J. T., Becker, J. C., Badaan, V., \& Sibley, C. G. (2019). Protesting to challenge or defend the system? A system justification perspective on collective action. European Journal of Social Psychology, 49, 244-269. https://doi.org/10.1002/ejsp. 2522.

Peer, E., Brandimarte, L., Samat, S., \& Acquisti, A. (2017). Beyond the Turk: Alternative platforms for crowdsourcing behavioral research. Journal of Experimental Social Psychology, 70, 153163. https://doi.org/10.1016/j.jesp.2017.01.006.

Pliskin, R., Ruhrman, A., \& Halperin, E. (2020). Proposing a multidimensional, context-sensitive approach to the study of ideological (a) symmetry in emotion. Current Opinion in Behavioral Sciences, 34, 75-80. https://doi.org/10.1016/j.cobeha.2020.01.005

Rankin, L. E., Jost, J. T., \& Wakslak, C. J. (2009). System justification and the meaning of life: Are the existential benefits of ideology distributed unequally across racial groups? Social Justice Research, 22, 312-333. https://doi.org/10.1007/ s11211-009-0100-9.

Richards, J. M., \& Gross, J. J. (1999). Composure at any cost? The cognitive consequences of emotion suppression. Personality and Social Psychology Bulletin, 25, 1033-1044. https://doi.org/10. 1177/01461672992511010.

Shepherd, L., Spears, R., \& Manstead, A. S. R. (2013). 'This will bring shame on our nation': The role of anticipated group-based emotions on collective action. Journal of Experimental Social
Psychology, 49, 42-57. https://doi.org/10.1016/j.jesp.2012.07. 011.

Shnabel, N., \& Ullrich, J. (2016). Putting emotion regulation in context: The (missing) role of power relations, intergroup trust, and groups' need for positive identities in reconciliation processes. Psychological Inquiry, 27, 124-132. https://doi.org/10.1080/ 1047840X.2016.1158538.

Solak, N. (2015). The role of emotions and emotion regulation in the system justification process [Unpublished doctoral dissertation, Middle East Technical University].

Solak, N., Jost, J. T., Sümer, N., \& Clore, G. (2012). Rage against the machine: The case for system-level emotions. Social Psychology and Personality Compass, 6, 674-690. https://doi.org/10.1111/j. 1751-9004.2012.00456.x.

Solak, N., Raifen Tagar, M., Cohen-Chen, S., Saguy, T., \& Halperin, E. (2017). Disappointment expression increases collective guilt and collective action in intergroup conflict: Moderating role of legitimacy perceptions. Cognition and Emotion, 31, 1112-1126. https://doi.org/10.1080/02699931.2016.1197098.

Srivastava, S., Tamir, M., McGonigal, K. M., John, O. P., \& Gross, J. J. (2009). The social costs of emotional suppression: A prospective study of the transition to college. Journal of Personality and Social Psychology, 96, 883-897. https://doi.org/10.1037/ a0014755.

Stuart, A., Thomas, E. F., \& Donaghue, N. (2018). "I don’t really want to be associated with the self-righteous left extreme": Disincentives to participation in collective action. Journal of Social and Political Psychology, 6, 242-270. https://doi.org/10.5964/jspp. v6i1.567.

Suppes, A., Napier, J. L., \& van der Toorn, J. (2019). The palliative effects of system justification on the health and happiness of lesbian, gay, bisexual, and transgender individuals. Personality and Social Psychology Bulletin, 45, 372-388. https://doi.org/10. 1177/0146167218785156.

Tackman, A. M., \& Srivastava, S. (2016). Social responses to expressive suppression: The role of personality judgments. Journal of Personality and Social Psychology, 110, 574-591. https://doi. org/10.1037/pspp0000053.

Tamir, M. (2016). Why do people regulate their emotions? A taxonomy of motives in emotion regulation. Personality and Social Psychology Review, 20, 199-222. https://doi.org/10.1177/10888 68315586325.

Thompson, R. A. (1994). Emotion regulation: A theme in search of definition. Monographs of the Society for Research in Child Development, 59, 25-52. https://doi.org/10.2307/1166137.

Toomey, P. (2018, August 22). The NSA continues to violate Americans' internet privacy rights. ACLU. Retrieved from https:// www.aclu.org/blog/national-security/privacy-and-surveillance/ nsa-continues-violate-americans-internet-privacy.

Turner-Zwinkels, F. M., \& van Zomeren, M. (2020). Identity expression through collective action: How identification with a politicized group and its identity contents differently motivated identity-expressive collective action in the US 2016 Presidential Elections. Personality and Social Psychology Bulletin. https:// doi.org/10.1177/0146167220933406.

Van Zomeren, M., Spears, S., Fischer, A. H., \& Leach, C. W. (2004). Put your money where your mouth is! Explaining collective action tendencies through group-based anger and group efficacy. Journal of Personality and Social Psychology, 87, 649-664. https://doi.org/10.1037/0022-3514.87.5.649.

Vargas-Salfate, S., Paez, D., Khan, S. S., Liu, J. H., \& Gil de Zúñiga, H. (2018). System justification enhances well-being: A longitudinal analysis of the palliative function of system justification in 18 countries. British Journal of Social Psychology, 57, 567-590. https://doi.org/10.1111/bjso.12254. 
Wakslak, C. J., Jost, J. T., Tyler, T. R., \& Chen, E. S. (2007). Moral outrage mediates the dampening effect of system justification on support for redistributive social policies. Psychological Science, 18, 267-274. https://doi.org/10.1111/j.1467-9280.2007.01887.x.

Webb, T. L., Miles, E., \& Sheeran, P. (2012). Dealing with feeling: A meta-analysis of the effectiveness of strategies derived from the process model of emotion regulation. Psychological Bulletin, 138, 775-808. https://doi.org/10.1037/a0027600.

Publisher's Note Springer Nature remains neutral with regard to jurisdictional claims in published maps and institutional affiliations. 